\title{
Insights Into Translatomics in the Nervous System
}

\author{
Shuxia Zhang ${ }^{1}$, Yeru Chen ${ }^{1}$, Yongjie Wang ${ }^{2,3}$, Piao Zhang ${ }^{1}$, Gang Chen ${ }^{1 *}$ and \\ Youfa Zhou' ${ }^{1}$
}

${ }^{1}$ Department of Anesthesiology, Sir Run Run Shaw Hospital, School of Medicine, Zhejiang University, Hangzhou, China, ${ }^{2}$ Key Laboratory of Elemene Anti-Cancer Medicine of Zhejiang Province and Holistic Integrative Pharmacy Institutes, Hangzhou Normal University, Hangzhou, China, ${ }^{3}$ Engineering Laboratory of Development and Application of Traditional Chinese Medicine from Zhejiang Province, Holistic Integrative Pharmacy Institutes, Hangzhou Normal University, Hangzhou, China

\section{OPEN ACCESS}

Edited by:

Gong Zhang,

Jinan University, China

Reviewed by:

Ta-Chien Tseng,

National Cheng Kung University,

Taiwan

Wanting Liu,

Jinan University, China

*Correspondence:

Gang Chen

chengang120@zju.edu.cn

Specialty section:

This article was submitted to

$R N A$,

a section of the journal

Frontiers in Genetics

Received: 29 August 2020 Accepted: 30 November 2020

Published: 21 December 2020

Citation:

Zhang S, Chen Y, Wang $Y$, Zhang P, Chen G and Zhou Y (2020) Insights Into Translatomics

in the Nervous System.

Front. Genet. 11:599548. doi: 10.3389/fgene.2020.599548
Most neurological disorders are caused by abnormal gene translation. Generally, dysregulation of elements involved in the translational process disrupts homeostasis in neurons and neuroglia. Better understanding of how the gene translation process occurs requires detailed analysis of transcriptomic and proteomic profile data. However, a lack of strictly direct correlations between mRNA and protein levels limits translational investigation by combining transcriptomic and proteomic profiling. The much better correlation between proteins and translated mRNAs than total mRNAs in abundance and insufficiently sensitive proteomics approach promote the requirement of advances in translatomics technology. Translatomics which capture and sequence the mRNAs associated with ribosomes has been effective in identifying translational changes by genetics or projections, ribosome stalling, local translation, and transcript isoforms in the nervous system. Here, we place emphasis on the main three translatomics methods currently used to profile mRNAs attached to ribosome-nascent chain complex (RNC-mRNA). Their prominent applications in neurological diseases including glioma, neuropathic pain, depression, fragile X syndrome (FXS), neurodegenerative disorders are outlined. The content reviewed here expands our understanding on the contributions of aberrant translation to neurological disease development.

Keywords: translatomics, RNC-mRNA, the nervous system, polysome profiling, ribosome profiling, translating ribosome affinity purification

\section{INTRODUCTION}

Gene expression is a cellular process involving the transcription, post-transcription modification, translation, messenger RNAs degradation, and protein turnover (Liu et al., 2016). Each step of this cascade shapes and balances gene expression. How this balance is achieved and the extent to which these processes contribute to protein synthesis is a long-standing open question. Although transcriptomic and proteomic techniques have greatly improved our ability to understand gene expression changes, significance is limited by a lack of strictly direct correlation between mRNA and protein levels, with some abundant mRNAs being poorly translated and vice versa. However, protein levels correlate better with mRNAs attached to ribosome-nascent chain complex (RNCmRNA) than with total mRNA levels, attaining a correlation of about 0.95 (Gygi et al., 1999; Greenbaum et al., 2003; Wang et al., 2013). Gene expression patterns derived from transcriptomic 
analysis corresponding to steady-state mRNA levels do not take translational control into consideration, which accounts for a large part of all regulatory amplitudes. Collectively, these observations highlight the importance of translational control. Indeed, various neurological diseases, including neuropathic pain (Colloca et al., 2017), neurodegenerative disorder (Poewe et al., 2017), multiple sclerosis (Filippi et al., 2018), fragile $X$ syndrome (FXS) (Hagerman et al., 2017) depression (AguilarValles et al., 2018) result from aberrant translation. Multiple studies have evaluated gene expression changes caused by external stimuli (Floriou-Servou et al., 2018) and neurological disorders (Shawahna et al., 2011; Donega et al., 2019) combining transcriptomic and proteomic profiling. However, their resolution is limited by high cellular heterogeneity (Sharma et al., 2015), alternative splicing (Su et al., 2018), translational regulation (Shigeoka et al., 2016), protein degradation (Daniele et al., 2018), and protein localization (Holt et al., 2019) likely causing the poor correlation seen between mRNAs and protein levels in the nervous system. Besides, insufficient sensitivity by proteomics limits detection of small amounts of newly synthesized protein that may accumulate in extremely narrow time windows, given that proteins are more stable (median halflife of $46 \mathrm{~h}$ ) than mRNAs (Schwanhäusser et al., 2011). In addition to translation, protein levels are also influenced by degradation, which is also tightly regulated. Consequently, it reinforces the requirement for RNA analysis at a point closest to the protein, then the translatome steps onto the stage to obtain more complete information of neurological development and dysfunction.

Polysome profiling, the first translatomics technique, has been valuable in translational studies - uncovering dynamics of ribosome occupancy and density. Ribosome profiling is another promising technique that can precisely determine mRNA localization on loaded ribosomes. Translating ribosome affinity purification (TRAP), which is widely used in nervous system studies, is suited for examining translation in specific cell types within complex brain tissues.

In this review, we discuss the generalized view of translatome, which covers almost all elements involved in translation, and how their dysregulation affects neurodevelopment. We then highlight how the three main translatomics methods identify mRNAs under translation and how they exert their functions in the neurological diseases. Next, the other reported applications of translatomics in the nervous system are concluded, which may lead to new ideas to study translational changes of neurological diseases. Finally, based on its application in other fields, we speculate on future translatomics applications in neuroscience.

\section{BROAD SENSE TRANSLATOMICS}

mRNA translation is the process by which the "base sequence" (nucleotide sequence) of mature mRNA molecules is used to synthesize corresponding specific amino-acid sequences. This highly dynamic process is divided into 4 crucial phases: initiation, elongation, termination, and ribosome recycling (Rodnina, 2018). In each phase, the ribosome and auxiliary translation factors form transient complexes that facilitate protein synthesis.
Figure 1 shows a schematic representation of translation (Kapur et al., 2017). Initiation involves assembly of a ternary complex (TC) including the $40 \mathrm{~S}$ ribosomal small subunit (SSU), the associated eukaryotic initiation factors (eIFs) and methionyltRNA (Met-tRNA ${ }^{\text {Met }}$ ) near the mRNA 5' cap; the SSU then scans along the mRNA in the $3^{\prime}$ direction until the P-site-bound MettRNA with anticodon is correctly paired with the mRNA start codon. the SSU is joined by the 60S ribosomal large subunit (LSU) to form the $80 \mathrm{~S}$ ribosome. The incoming aminoacyltRNA (aa-tRNA) with the complementary codon enters the ribosome A site, and elongation commences. A peptide bond is established between the incoming amino acid of the $\mathrm{A}$ site and the adjacent amino acid of peptidyl-tRNA in the ribosomal $\mathrm{P}$ site. Once a peptide bond is formed, the ribosome slides forward relative to the mRNA triggering translocation of the tRNAs into the canonical P- and E-sites. Translation termination occurs when a stop codon enters the A site of ribosome. The nascent polypeptide chains release, then the ribosome dissociates into separate subunits and escapes from the mRNA.

The term translatome refers to the totality of elements directly involved in translation, including ribosomes, RNCmRNA, tRNA, regulatory RNA (such as miRNA and lncRNA), RNA binding proteins, and various translation factors (Zhao et al., 2019). Impaired function by these elements is associated with a range of pathophysiological changes in the nervous system (Table 1).

Translation is executed by ribosomes (Peña et al., 2017), which are comprised of a $60 \mathrm{~S}$ subunit that possesses 3 ribosomal RNAs (25S, 5.8S, 5S) and 47 proteins, and a $40 \mathrm{~S}$ subunit containing $18 \mathrm{~S}$ ribosomal RNA and 33 ribosomal proteins. Ribosomopathies are a diverse group of disorders associated with aberrant ribosome production and function (Mills and Green, 2017). Impaired expression of ribosomal genes in the brain causes ribosome biogenesis abnormalities in mice suffering from chronic social defeat stress (Smagin et al., 2016). Using X-exome resequencing, a mutation affecting RPL10, a $60 \mathrm{~S}$ ribosomal protein, causes neurodevelopmental defects and X-linked disorders (Zanni et al., 2015; Slomnicki et al., 2016). Thus, dysregulation of ribosomal biogenesis and function may disrupt neurodevelopment, leading to microcephaly and cognitive impairment (Ingolia et al., 2009; Darnell, 2014; Ishimura et al., 2014; Zanni et al., 2015; Slomnicki et al., 2016). Using conventional biochemical methods, knockout or knockdown of ribosome proteins in neurons could mimic the observed impaired ribosomal biogenesis in neurodegenerative diseases and study their pathogenic contributions (Slomnicki et al., 2018). The structural biology method has also made remarkable contributions to the ribosome field. Our current understanding of ribosome structure and function has been greatly expanded after the emerging of X-ray crystallography and cryogenic electron microscopy (cryo-EM) (Wilson and Doudna Cate, 2012; von Loeffelholz et al., 2017). High-resolution features of cryo-EM has enabled the visualization of chemical modifications of the ribosomal RNA and the ligand complexes of the ribosome (Myasnikov et al., 2016; Javed et al., 2017; von Loeffelholz et al., 2017). Cryo-EM has been used to analyze the structure of receptors and ion channels in neurons 

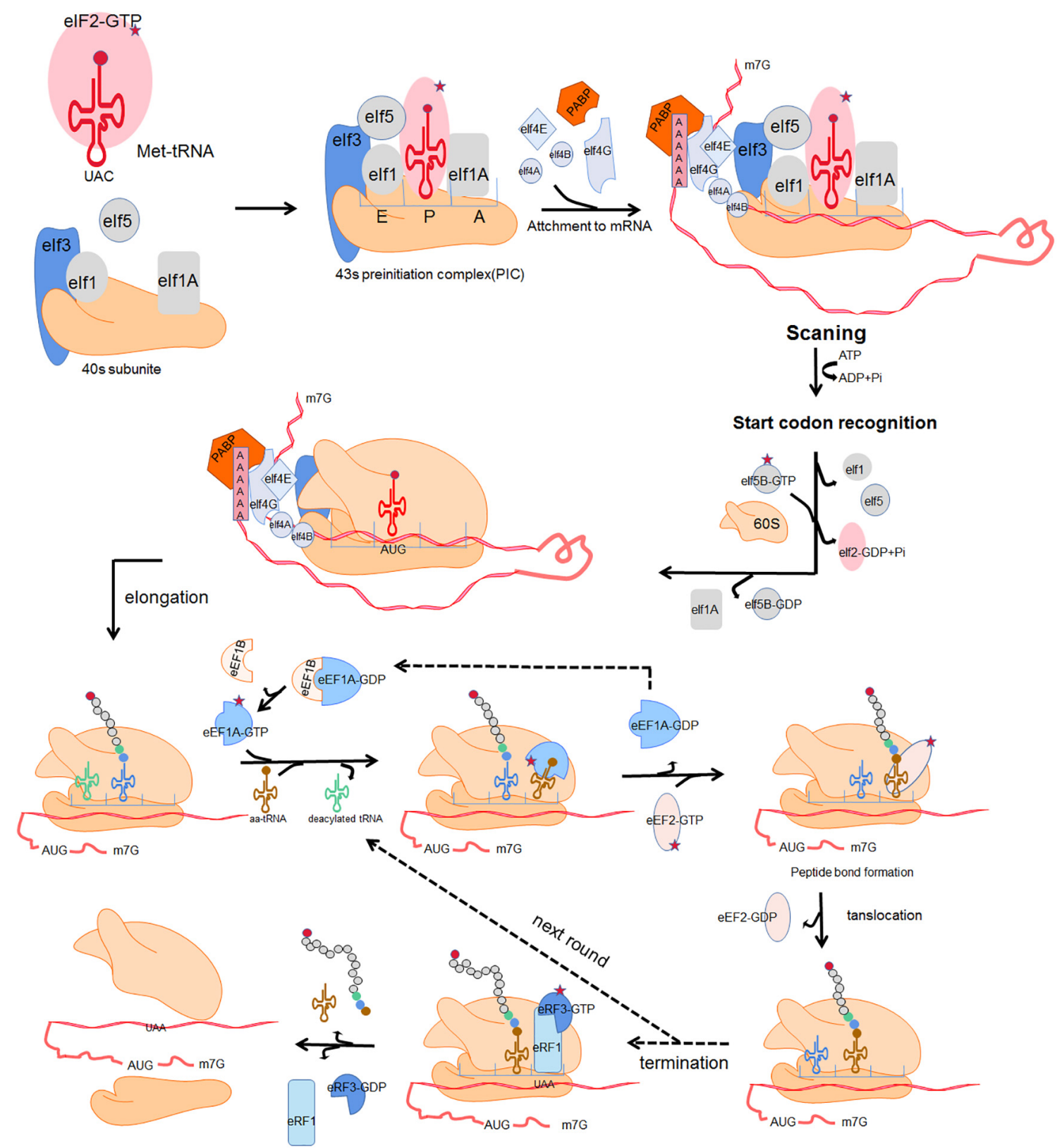

FIGURE 1 | Four fundamental phases of translation:initiation, elongation, termination and ribosome recycle. Initiation: a ternary complex (TC) comprising a GTP-bound eukaryotic translation initiation factor 2 (elF2) and methionyl-tRNA (Met-tRNA ${ }^{\text {Met}}$ ) interacts with the 40s ribosomal subunit and several initiation factors including eukaryotic translation initiation factor 1 (elF1), eukaryotic translation initiation factor 1A (elF1A), eukaryotic translation initiation factor 5 (elF5) and eukaryotic translation initiation factor 3 (elF3), forming an 43s preinitiation complex (43s PIC). The 43s PIC is recruited to the mRNA $5^{\prime}$ cap through the eukaryotic translation initiation factor $4 \mathrm{~B}$ (elF4B) and eukaryotic translation initiation factor $4 \mathrm{~F}$ (elF4F) which is composed of eukaryotic translation initiation factor $4 \mathrm{~A}$ (elF4A), eukaryotic translation initiation factor $4 \mathrm{E}$ (elF4E) and eukaryotic translation initiation factor 4G (elF4G). Poly(A)-binding protein (PABP) together with elF4G acts as a bridging factor which mediates "closed loop" mRNA conformation. The 43s PIC then scans along the mRNA until the P-site-bound Met-tRNA with anticodon is correctly paired with the mRNA start codon. Subsequently the dissociation of elF2 and other eukaryotic initiation factors trigger the combination of the 60S and the 40S ribosomal subunit, forming a complete 80 s ribosome and allowing the second codon to be decoded at the A site. Elongation: the incoming aminoacyl-tRNA (aa-tRNA) with the complementary codon enters the ribosome A site, facilitated by eukaryotic translation elongation factor $1 \mathrm{~A}$ (eEF1A) and eukaryotic translation elongation factor $1 \mathrm{~B}$ (eEF1B). A peptide bond is established between the incoming amino acid of the A site and the adjacent amino acid of peptidyl-tRNA in the ribosomal $\mathrm{P}$ site. Subsequently, the nascent peptide of the $\mathrm{P}$ site leaves its tRNA and binds to the amino group of the A-site aminoacyl-tRNA. Once a peptide bond is formed, the ribosome slides forward relative to the mRNA triggering translocation of the tRNAs into the canonical P-and E-sites. This is promoted by eukaryotic translation elongation factor 2 (eEF2) with transposase activity at the cost of GTP hydrolysis. The release of E-site deacylated tRNA occurs before the next aminoacyl-tRNA enters into the vacant A site. Termination and ribosome recycle: translation termination occurs when a stop codon enters the A site of ribosome. In eukaryotes, eukaryotic release factor 1 (eRF1) and eukaryotic release factor 3 (eRF3) hydrolyze the ester bond of the peptidyl-tRNA, driving the translation termination and ultimately triggering the release of nascent polypeptide chains. The ribosome dissociates into separate subunits and escapes from mRNA. 
TABLE 1 | Elements involved in translation and the application of translatomics in nervous system diseases.

\begin{tabular}{|c|c|c|c|}
\hline Elements & & Conclusions & References \\
\hline Ribosome & \multicolumn{2}{|c|}{$\begin{array}{l}\text { Dysregulation of ribosomal biogenesis } \\
\text { disrupts neurodevelopment. }\end{array}$} & Zanni et al., 2015; Slomnicki et al., 2016, 2018 \\
\hline tRNA & \multicolumn{2}{|c|}{$\begin{array}{l}\text { Interruption of tRNA maturation and modification } \\
\text { drives nervous system dysfunctions. }\end{array}$} & $\begin{array}{l}\text { Karaca et al., 2014; Ivanova et al., 2017; Lin et al., 2018; } \\
\text { Ramos and Fu, 2019; Schaffer et al., 2019; Torres et al., } \\
2019\end{array}$ \\
\hline $\begin{array}{l}\text { Auxiliary translation } \\
\text { factors }\end{array}$ & \multicolumn{2}{|c|}{$\begin{array}{l}\text { Initiation factors (e.g., elF4E and elF2 } \alpha \text { ) and elongation factors } \\
\text { (e.g., eEF1A and eEF2) are involved in neurodevelopment } \\
\text { and maintenance of synaptic plasticity. }\end{array}$} & $\begin{array}{l}\text { Beckelman et al., 2016; Amorim et al., 2018; } \\
\text { Jan et al., 2018; Tsai et al., 2018; Uttam et al., 2018b; } \\
\text { Zyryanova et al., } 2018\end{array}$ \\
\hline \multirow[t]{3}{*}{ Regulatory RNAs } & \multicolumn{2}{|c|}{ Inhibit translation, mediated by microRNAs decreasing protein levels. } & $\begin{array}{l}\text { Schratt et al., 2006; Murphy et al., 2017; Zhang H. et al., } \\
\text { 2018; Chen et al., } 2020\end{array}$ \\
\hline & \multicolumn{2}{|c|}{ IncRNAs and circRNAs function as competing endogenous RNAs } & \\
\hline & \multicolumn{2}{|c|}{ by sponging microRNAs in neuronal cells. } & \\
\hline \multirow[t]{3}{*}{ RNA binding proteins } & \multirow{2}{*}{\multicolumn{2}{|c|}{$\begin{array}{l}\text { Some RNA binding proteins (e.g., FMRP and PUM2) repress } \\
\text { the translation of their target mRNAs. }\end{array}$}} & Chen et al., 2014; D’Amico et al., 2019 \\
\hline & & & Chen et al., 2014; D’Amico et al., 2019 \\
\hline & Diseases & Conclusions & \\
\hline \multirow[t]{5}{*}{ RNC-mRNAs } & Glioma & $\begin{array}{l}\text { Polysome profiling gives the first insight into the } \\
\text { radiation and drug resistance of GBM cells at } \\
\text { the translation level. }\end{array}$ & Wahba et al., 2016, 2018; Bell et al., 2018 \\
\hline & Neuropathic Pain & $\begin{array}{l}\text { Nav1.8-TRAP mice could achieve sensory } \\
\text { neuron-specific ribosome tagging with } \\
\text { enrichment in the nociceptor population and } \\
\text { facilitate the finding of new mechanisms } \\
\text { controlling nociceptor excitability. } \\
\text { Axon-TRAP is likely lead to important } \\
\text { breakthroughs in our understanding of which } \\
\text { mRNAs are translated locally in nociceptor } \\
\text { axons to modulate excitability. }\end{array}$ & Shigeoka et al., 2016; Megat et al., 2019a,b \\
\hline & Depression & $\begin{array}{l}\text { Astroglial-specific bacTRAP connects } \\
\text { perineuronal net, astroglial cells, and } \\
\text { depression. Similarly, } \\
\text { ePet-Cretg/- } / \text { RiboTag }{ }^{t g /-} \text { mice link FKBP5 and } \\
\text { serotonin with depression. }\end{array}$ & Simard et al., 2018; Lesiak et al., 2020 \\
\hline & Fragile $X$ syndrome & $\begin{array}{l}\text { Ribosome profiling can distinguish stalled and } \\
\text { active ribosomes, and uncovered the } \\
\text { contribution of ribosomal brake -FMRP to } \\
\text { fragile X syndrome. }\end{array}$ & Das Sharma et al., 2019; Shah et al., 2020 \\
\hline & $\begin{array}{l}\text { Neurodegenerative } \\
\text { diseases }\end{array}$ & $\begin{array}{l}\text { TRAP method targeting cell types defined by } \\
\text { genetics or projections can effectively profile } \\
\text { translation regulation on memory consolidation } \\
\text { associated with Alzheimer's disease. } \\
\text { Accurately interference with the translation } \\
\text { mechanism in specific cells of targeted regions } \\
\text { may be a novel therapeutic target for } \\
\text { neurodegenerative diseases. }\end{array}$ & $\begin{array}{l}\text { Cho et al., 2015; Ostroff et al., 2019; Voskuhl et al., 2019; } \\
\text { Kim et al., 2020; Lim et al., } 2020\end{array}$ \\
\hline
\end{tabular}

(Dang et al., 2017; Laverty et al., 2019; Liu et al., 2019), but few studies have reported ribosomopathies under cryo-EM.

Disruption in tRNA maturation and modification can alter the amount of cellular tRNA, thereby damaging protein folding and affecting neuronal homeostasis, which may result in nervous system dysfunction (Blanco et al., 2014; Kapur et al., 2017; Musier-Forsyth, 2019). tRNA aminoacylation by tRNA synthetases is a critical quality control checkpoint for maintaining translation fidelity. Mutations in aminoacyl-tRNA synthetases are implicated in a wide range of nervous system disorders (Meyer-Schuman and Antonellis, 2017; Ognjenović and Simonović, 2018). Various factors have linked tRNA dysfunction to neurological disorders, including a genomic mutation that reduces the expression of isodecoder, which has the same anticodon as tRNA but differs in the tRNA body sequence (Torres et al., 2019), mutations affecting tRNA splicing machinery (Karaca et al., 2014; Ivanova et al., 2017), aberrant expression of tRNA metabolism genes (Schaffer et al., 2019), and impaired tRNA modification (Lin et al., 2018; Ramos and $\mathrm{Fu}, 2019$ ) all point to an association between defective tRNA function and neurological disorders. Recently, DM-tRNAseq (demethylase tRNA sequencing), modified charged DMtRNA-seq and ARM-seq (AlkB-facilitated RNA methylation sequencing) have developed to identify and quantify tRNA base modification (Cozen et al., 2015; Zheng et al., 2015; Evans et al., 2017). These advances have not been applied to the neuronal field, 
but future applications of these technologies may provide a more comprehensive explanation of the role of tRNA dysfunction in nervous system diseases.

Eukaryotic translation initiation factor 4E (eIF4E) phosphorylation by MNK (MAPK-interacting protein kinase) modulates excitatory synaptic activity and depression-like behavior (Amorim et al., 2018). Additionally, eIF4E integrates inputs from ERK (extracellular regulated protein kinases) and mTORC1 (mammalian target of rapamycin complex 1) signaling, and has been shown to influence pain plasticity (Uttam et al., 2018b). eIF $2 \alpha$ (eukaryotic translation initiation factor $2 \alpha$ ) phosphorylation converts itself into a competitive inhibitor of eIF2B (eukaryotic translation initiation factor $2 \mathrm{~B}$ ), a guanine nucleotide exchange factor, thereby aggravating cognitive deficits after traumatic brain injury (Tsai et al., 2018; Zyryanova et al., 2018). Other translation initiation and elongation factors, including eukaryotic elongation factor 1A (eEF1A), and eukaryotic elongation factor 2 (eEF2), are involved in neurodevelopment and long-term synaptic plasticity (Beckelman et al., 2016; Jan et al., 2018). However, few studies have examined the role of eukaryotic release factors in neurological disorders.

Non-coding RNAs and RNA binding proteins have emerged as key regulators in the nervous system. miRNAs (micro RNAs) modulate protein levels by typically binding to the $3^{\prime}$ untranslated region of cytosolic mRNA targets, triggering mRNA degradation (Germany et al., 2019). miR-134, a brain-specific miRNA negatively modulates synapse development by inhibiting LIM kinase 1 protein translation (Schratt et al., 2006). miR-144$3 p$ represses translation and is linked to the rescue of anxiety-like behavior (Murphy et al., 2017). Mounting evidence indicate that lnc-RNA (long non-coding RNAs) and circRNAs (circular RNAs) act as competing endogenous RNAs by sponging microRNAs in neuronal cells (Zhang H. et al., 2018; Chen et al., 2020). FMRP (fragile X mental retardation protein), an RNA binding protein, appears to directly bind to the $80 \mathrm{~S}$ ribosome, thereby repressing translation of target mRNAs, and has been linked to autism (Darnell et al., 2011; Chen et al., 2014). The RNAbinding protein, PUM2 (Pumilio2), inhibits translation of genes involved in mitochondrial homeostasis and is induced in the aging brain (D'Amico et al., 2019). Deletion of Lin28, an RNA binding protein, is associated with brain developmental defects (Herrlinger et al., 2019).

Ribosome-nascent chain complex, an intermediate product of translation, will be discussed in detail under narrow translatomics. Detailed analysis of mRNA translation, including translation rates, can provide insight into the regulatory effects of broad translatomic components in the nervous system (Darnell et al., 2011). Collectively, the above evidences show that orderly translation is essential for maintaining neuronal homeostasis and aberrant translational elements contribute to neurological diseases.

\section{NARROW SENSE TRANSLATOMICS}

In the narrow sense, translatomics refers to investigation translating mRNA in order to elucidate translational changes.
Due to non-covalent interaction between ribosomes and mRNA, ribosomal nascent-chain complexes are highly unstable and tend to dissociate during cell lysis, increasing chances of enzymatic degradation (Zhao et al., 2019). Multiple approaches, including microarray-based sequencing and RNA sequencing (RNA-Seq) have been developed for transcriptome identification and quantification (Wang et al., 2009). Based on RNC features and transcriptomics methods, multiple techniques have been developed for analyzing translation, including polysome profiling, ribosome profiling (Ribo-seq) and translating ribosome affinity purification (TRAP-seq) (Figure 2; Zhao et al., 2019). Here, we will review technical advances that have provided insight into translational regulation in nervous system diseases.

\section{Polysome Profiling}

One or more ribosomes recruit identical mRNA with the translation rate being limited by initiation rate. Thus, ribosome density on a given mRNA reflects translational status. Polysome profiling is a technique developed in the 1960s that relies on sucrose density gradient ultracentrifugation and fractionation (Drysdale and Munro, 1967). mRNAs bound to varying numbers of ribosomes can be separated via centrifugation (King and Gerber, 2016). Polysomes and monosomes are often separated through a standard linear sucrose gradient (commonly 5$50 \%$ sucrose) made by a gradient maker (Liang et al., 2018). Gradients are collected into several fractions, some of which are translating mRNAs associated with polysomes, monosomes and the supernatant containing the free mRNAs, $60 \mathrm{~S}$ and $40 \mathrm{~S}$ ribosomal subunits (Figure 2). The height of polysome peaks of the curve and the area under each peak indicate ribosome translational activity (Figure 2). Northern blot, RTqPCR, as well as the high-throughput microarray or RNA-seq approaches are then used to identify mRNAs in the separated components (Figure 2). Initiation inhibition causes ribosome "runoff," leading to decomposition of polysome and elevated levels of free ribosomal subunits. Elongation inhibition enhances polysomal size. Detection of similarly sized polysomes in different circumstances suggests that initiation and elongation have both been affected or translation activity is unchanged (Gandin et al., 2014). The unfeasibility of handling many samples in parallel limits wide use of polysome profiling. Furthermore, it is difficult to distinguish between stalled ribosomes and active polysome whose distribution may change within the high fraction (Sivan et al., 2007). These challenges can be partly surmounted by ribosome profiling (see details below).

\section{Ribosome Profiling}

Previously, there have been no ways to directly quantify protein synthesis rates. Thus, studies of translational regulation have relied on comparing mRNA and protein levels. Although polysome profiling may estimate protein synthesis, this approach has low resolution and accuracy. Ingolia et al. developed the ribosome profiling method in which the ribosome-nascent peptide chain complex is nuclease-treated to destroy mRNA fractions that are not occupied by ribosomes (Figure 2; Ingolia et al., 2009). Ribosome-protected fractions (RPFs) are then isolated by sucrose density gradient centrifugation or 


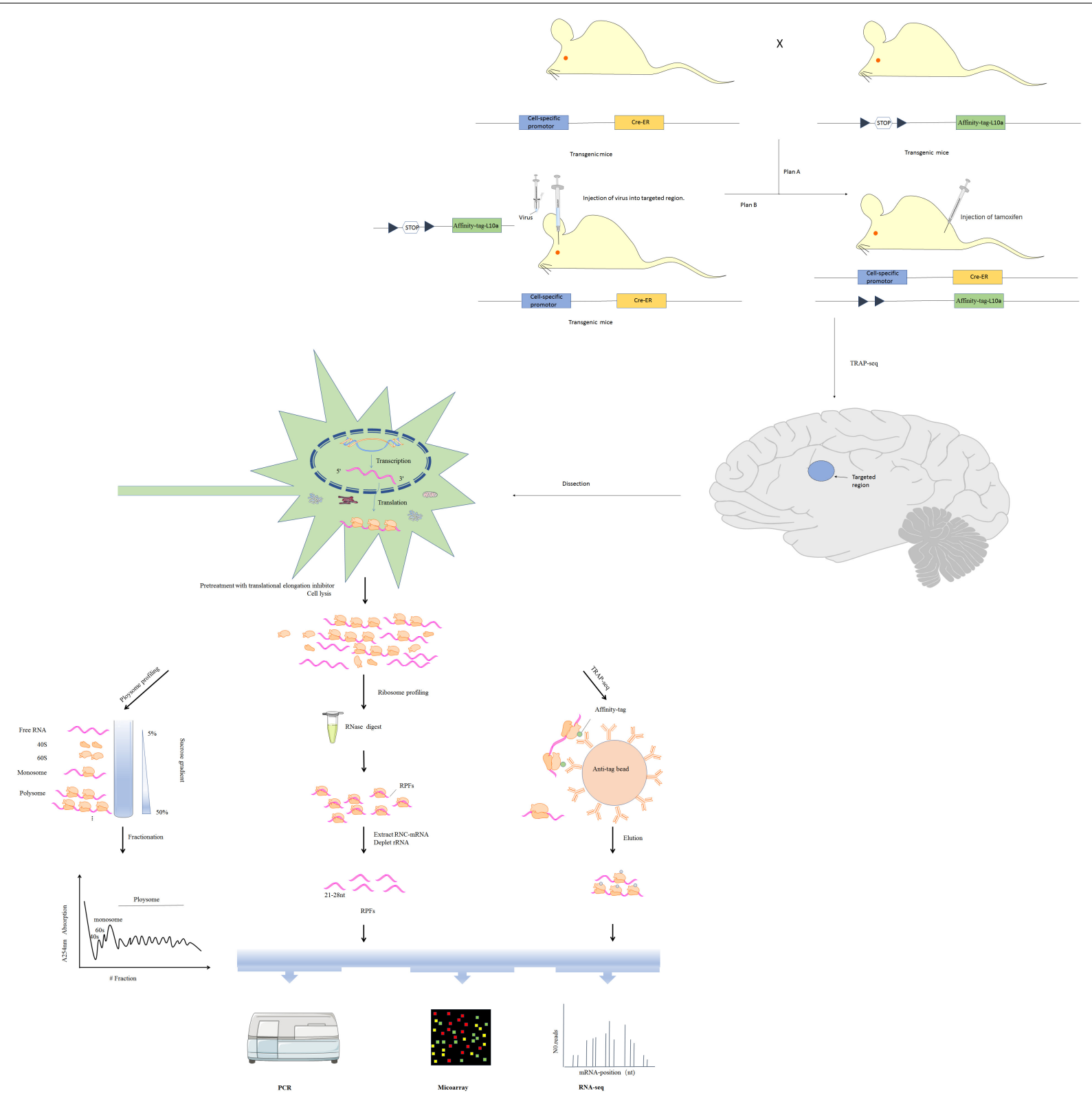

FIGURE 2 | Three major translatomic methods investigating RNC-mRNAs [modified from Figure 1 in Zhao et al. (2019)]. Polysome profiling: utilizing features of the largest ribosome sedimentation coefficient in most cells and separating translating mRNAs with polyribosomes by sucrose density gradient ultracentrifugation and fractionation. Ribosome profiling: treating the ribosome-nascent peptide chain complex with ribonuclease to degrade mRNA fragments that are not covered by ribosomes, and isolating ribosomes protected fractions (RPFs). TRAP-seq: isolating RNC-mRNAs of specific cell type by affinity purification with corresponding anti-tag beads, under the control of a cell-specific promoter and an affinity tag (such as His, Avi, GFP, etc.) which is fused into the large ribosomal subunit (such as Rpl10a protein). The construction of transgenic cre mice expressing Rpl10a protein with affinity tag in specific cell in the nervous system is shown.

immunopurification of ribo-tag cells (Ingolia et al., 2012). After ribosome and rRNA removal, high-throughput sequencing is used to detect small, ribosome-protected, RNA fragments of about 21-28 bp. This approach has multiple advantages. High-resolution ribosome footprints (RFs) enable genome-wide analysis of translation with codon resolution and can: (i) elucidate translational efficiency of all individual mRNAs as calculated from ribosome profiling paired with RNA-seq (Ingolia et al., 2009), (ii) detect even relatively rare and subtle translation events (Brar and Weissman, 2015), (iii) uncover rich and precise ribosome positional information, such as translation initiation at non-AUG codons (Spealman et al., 2018), identify upstream ORFs (uORFs) translation (Rodriguez et al., 2019), as well as elucidate codon usage bias (Paulet et al., 2017) and ribosome pausing (Michel et al., 2012).

The availability of commercial kits has greatly simplified ribosome profiling. However, its efficiency in accurately measuring mRNA translation efficiency is limited by the 
following factors: (i) independent biases caused by ribonuclease digestion (Gerashchenko and Gladyshev, 2017), (ii) biases introduced by translation elongation inhibitors, for example, anisomycin and cycloheximide favor $21 \mathrm{nt}$ RPFs and $28 \mathrm{nt}$ RPFs, corresponding to ribosomes with open and occupied A sites, respectively (Lareau et al., 2014; Wu et al., 2019), (iii) relatively high false positive and negative rates due to bias toward analysis of main coding sequences (CDS) and lack of rRNA probes for complete rRNA depletion (Guttman et al., 2013; King and Gerber, 2016).

\section{TRAP-Seq}

Isolation of full-length mRNAs associated with ribosomes has been conventionally done via polysome profiling. However, this approach is time-consuming and limited to handling large numbers of samples in parallel. Alternatively, translating ribosome affinity purification sequencing (TRAP-seq) based on expressing tagged ribosomal proteins has been reported (Inada et al., 2002). By using animals or cells in which activated crerecombinase under a cell-specific promoter drives expression of an affinity tag (such as His, Avi, or GFP) fused to the large ribosomal subunit, RNC-mRNAs of specific cell type may be isolated by affinity purification with corresponding anti-tag beads (Figure 2; Heiman et al., 2014). This approach is limited by the need to generate stably transfected cell lines or transgenic animals for cell type. The potential biases of this method are that some ribosomal proteins including RPL10a preferentially translate specific mRNAs (Xue and Barna, 2012), and that some isolated mRNAs may be extraribosomal.

Translating ribosome affinity purification sequencing is seldomly used in other fields. However, it is especially important in the nervous system because it is relatively difficult to reliably obtain translational descriptions of specific cells from the central nervous system tissues due to its complex cellular heterogeneity (Okada et al., 2011). Although Fluorescence Activated Cell Sorting (FACS) method has been able to isolate specific cells of brain and Schwann cells of the peripheral nervous system (Rubio et al., 2016; Germany et al., 2019; Tomlinson et al., 2020), it takes one whole day to dissociate the tissue and isolate cells by FACS (Rubio et al., 2016). Thus, it may change gene translational expression patterns and limit the utility of timeconsuming translatomics methods including polysome profiling and ribosome profiling. In this case, TRAP-seq may be the only practical way to investigate cell-type specific translation for neuron cells and Schwann cells.

\section{Other Translatomics Method}

It is widely accepted that actively translating mRNAs bind multiple ribosomes. However, this is contradicted by recent findings that translation occurs also on mRNAs bound to monosomes, and that translation is not directly proportional to the number of ribosomes on mRNA (Requião et al., 2017; Neidermyer and Whelan, 2019; Biever et al., 2020). Relative to standard linear gradient of polysome profiling, nonlinear gradients of RNC-seq (full-length translating mRNA sequencing) enable translating mRNAs elution at smaller volumes to circumvent the limitations of polysome profiling
(Liang et al., 2018). In the RNC-seq approach, cell lysate is transferred to the surface of $30 \%$ sucrose buffer and the bottom pellet containing RNC-mRNAs collected from the sucrose solution after ultracentrifugation (Liu et al., 2018; Zhang M. et al., 2018). Although high-resolution ribosome profiling defines elongating ribosomes along mRNA, it cannot record intermediates of translation initiation, termination and recycling. To address this, Stuart K. Archer et al. developed translation complex profile sequencing (TCP-seq) method which developed from ribosome profiling (Archer et al., 2016). The yeast cells were crosslink with formaldehyde to stall ribosomes and attach translation complex to mRNA at native positions. Then translation complex subjected to RNase digestion. Next, the ribosome and small subunit (SSU) were separated by sucrose gradient ultracentrifugation, and the 250 nt-long RNA fragments on these fragments were sequenced to obtain the naturally distributed map at the initial, extension and termination stages of translation, respectively. The method is capable of observing the SSU footprint on the $5^{\prime}$ untranslated region (UTR) of mRNA and capturing the position of any type of ribosome -mRNA complex at various stages of translation. For valuable, limited amounts of nervous system tissue, RNC-seq seems superior to polysome profiling. However, RNC-seq and TCP-seq are seldomly used in neurology field, probably because they are relatively new and not known to most neurologists.

\section{Applications of Translatomics for Neurological Disease}

Each method of translatomics has its own unique application and advantages. Polysome profiling, the first translatomics technique, can measure ribosome density and fractionate RNA based on ribosome occupancy. Methods that provide precise mRNA positional information of ribosome occupancy can accurately estimate translation rate. TRAP, which is the most widely used in nervous system studies can analyze translation in specific cell types. To better show the role of translatomics in the nervous system, we focused on the application of polysome profiling in glioma disease, ribosome profiling in FXS and Parkinson's disease (PD) by virtue of ribosome stalling identification. TRAP in neuropathic pain, depression, multiple sclerosis (MS), and memory consolidation associated with Alzheimer's disease (AD) through targeting cell types defined by genetics or projections and monitoring local translation.

\section{Glioma}

In polysome fractionation, the height of polysome peaks and the area under each peak indicate ribosome translational activity. Brain cancer such as Glioblastoma Multiforme (GBM) which is an intrinsic and highly heterogeneous tumor of the brain has been studied by the classic and affordable methodology of polysome profiling due to having a variety of recognized tumor cell lines (Westphal and Lamszus, 2011). Analysis of translational rate, expressed as the ratio of area under the polysome and $80 \mathrm{~S}$ peaks, and analysis of total and translating mRNAs levels by combining tanslatome and transcriptome methods, revealed for the first time that translating mRNAs can act as biomarkers for glioblastoma 
and previously unappreciated GBM heterogeneity (Bernabò et al., 2017; Lupinacci et al., 2019).

Glioblastoma stem cells (GSCs) within GBM can self-renew, differentiate into distinct lineages and escape current therapeutic approaches including radiotherapy and chemotherapy (Bayin et al., 2014). Overcoming the escape mechanism could make substantial progress toward an more effective treatment. As a clonogenic subpopulation, the GSC lines are critical to study the treatment response of glioblastomas, and thus polysome profiling with high demand for sample size was widely used. Wahba et al. analyzed radiation-induced translatomes and put forward new molecular insights concerning GBM radiosensitization such as Golgi dispersal and increased eIF4F-cap complex formation detected after radiation (Wahba et al., 2016). Radiation primarily modifies gene expression via translational control (Wahba et al., 2016). Moreover, the nuclear export protein XPO1 in the interacting network based on translatome data was identified to serve as a key molecule for radiosensitization in GSCs (Wahba et al., 2018). Of significance, in vitro and in vivo experiment proved that the XPO1 inhibitor selinexor enhanced the radiosensitivity of GSCs by inhibiting DNA repair. In addition to radioresistance, drugresistance also needs to be solved. Proneural (PN) and mesenchymal (MES) GSCs are two mutually exclusive GSC populations with distinct dysregulated signaling identified by genome-wide transcriptional analysis (Nakano, 2015). The two subtypes drive therapeutic resistance in glioblastoma. It has been showed that arsenic trioxide (ATO) drug is more potent and inhibitory to PN GBM cells than to MES GBM cells. ATO activates the MAPK-interacting kinase 1 (MNK1)-eukaryotic translation initiation factor 4E (eIF4E) signaling axil, and MNK activation associates with ATO resistance (Bell et al., 2016). Given this information, Bell et al. used polysomal fractionation to analyze an ATO-induced translatome and found an enrichment of anti-apoptotic mRNAs, suggesting translation-mediated resistance to ATO in MES GSCs (Bell et al., 2018). Furthermore, in an apoptosis assay, inhibition of MNK sensitized MES GSCs to ATO (Bell et al., 2018). This finding raises a possibility that targeting MNK1 makes MES GSCs sensitive to drugs such as arsenic trioxide. Collectively polysome profiling gives insight into the radiation and drug resistance of GBM cells at the translation level.

\section{Neuropathic Pain}

Neuropathic pain is a disorder that features spontaneous persistent or shooting pain after nerve injury. Translational regulation is key in nociceptive circuits and altered mRNA translation is involved in the sensitization of nociceptors in response to nerve injury (Khoutorsky and Price, 2018).

Dorsal root ganglion (DRG) and trigeminal ganglion (TG) neurons are remarkably nociceptive. Which mRNAs translation has been changed in nociceptors causing neuropathic pain is unclear. Translatomics methods can help to solve this problem. The most straightforward application of TRAP is the systematic molecular characterization of target cell types in complex tissues, including the brain, from which neurons are extremely difficult to isolate. Doyle et al. used 16 transgenic mouse lines to compare translational profiling of distinct cell types of the nervous system
(Doyle et al., 2008). This versatile strategy could molecularly characterize specific cell types even in the most heterogeneous cell populations in vivo. Thus, TRAP complements standard cell sorting approaches that may be influenced by artifacts and bias toward some subtypes (Haimon et al., 2018; Huang et al., 2019). Regardless, droplet-sequencing (Drop-seq), like single-cell approaches, have advanced enough to enable counting of specific cell types (Saunders et al., 2018), and TRAP remains a convenient way of investigating translational regulation.

A recent study used Nav1.8-TRAP mice to achieve sensory neuron-specific ribosome tagging with enrichment in the nociceptor population (Megat et al., 2019a). This unbiased method demonstrated a novel translation regulation signaling circuit causing chemotherapy-induced neuropathic pain (CIPN). Mitogen-activated protein kinase interacting kinase (MNK) and eukaryotic initiation factor (eIF) $4 \mathrm{E}$ activity acted on the target of rapamycin complex 1 (mTORC1) via control of RagA translation in Nav1.8-TRAP mice with CIPN (Megat et al., 2019a). In the same mice, they observed higher enrichment in mechanistic target of rapamycin (mTOR)-related genes in the TG-TRAP dataset compared with DRG, whereas translational efficiency in AMP-activated protein kinase related genes was higher in the DGR. Moreover, capsaicin stimulation of the TG region caused greater pain responses than stimulation of DRG-innervated regions (Megat et al., 2019b). This finding is in line with the fact that the mTORC1 signaling pathway plays a key role in controlling nociceptor excitability and sensitization, and this sensitization is strongly weakened by AMPK pathway activation (Schmidt et al., 2016). The several published studies on pain mechanisms and translatomics almost entirely limited to the peripheral nervous system, and the only one targeting the central nervous system was performed by Uttam et al. (2018a), who adopted the ribosome profiling approach to identify mRNAs with significantly changed translational efficiency in spinal cord dorsal horn tissues after spared nerve injury (SNI).

Multiple studies have confirmed that translation also occurs at decentralized local neuronal domains that are highly polarized, such as in the peripheral nervous system (PNS) axonal and central nervous system (CNS) dendritic compartments (Glock et al., 2017). IL-6 and NGF in primary afferent neurons and their axons cause nascent protein synthesis by enhancement of the eIF4F complex formation to induce pain hypersensitivity in vitro (Melemedjian et al., 2010). Inhibition of protein synthesis with local administration of rapamycin in myelinated axons of the rodent foot pad was shown to prevent capsaicin-induced hyperalgesia (Jiménez-Díaz et al., 2008). The local translation regulation mechanism has a key role in the establishment and maintenance of chronic pain. Despite evidence indicating that mature axons are capable of protein synthesis (Kalinski et al., 2015; Rangaraju et al., 2017), the small size of axons and tight connections with glia and post-synapses have made in vivo transcriptome and translatome isolation extremely challenging. Importantly, microdissection-based approaches are limited to brain regions (e.g., the hippocampus; (Biever et al., 2020) where axons are in separable lamina. While abundant transcriptome analysis demonstrated that the mRNAs for cAMP-response element binding protein (CREB), $\mathrm{Na}_{v} 1.8$, and other ion channels 
localize to DRG axons in vitro (Thakor et al., 2009; Melemedjian et al., 2014; Hirai et al., 2017), there are technological challenges to research in which mRNAs are translated locally in nociceptor axons in vivo. TRAP-seq has overcome this limitation. Because the axons of retinal ganglion cells terminate in the superior colliculus of the midbrain, Shigeoka et al. used axon-TRAP, in which the cyclization recombination enzyme is only expressed in retinal ganglion cells, and immunopurified mRNAs on ribosomes in developing and mature axons from the dissected superior colliculus (Shigeoka et al., 2016). Axon-TRAP may expand our understanding of which mRNAs are locally translated to regulate excitability in nociceptor axons.

\section{Depression}

According to the World Health Organization, at least 350 million people are affected by depression worldwide (Smith, 2014). Depression, one of the psychiatric disorders, has become a growing health concern. Several studies have reported the involvement of astroglial cells in depression, and significant changes in astrocytes in response to antidepressants (Banasr and Duman, 2008; Nagy et al., 2015; Peng et al., 2015). However, the nature of these significant changes remains largely unknown. Simard et al. employed astroglial-specific bacTRAP mice exposed to chronic variable stress (CVS) to generate a translatomic database of differentially expressed genes (DEGs). Analysis of top DEGs indicated that CVS impaired perineuronal net (PNN) degradation, resulting in neuroplastic dysfunction (Simard et al., 2018). Subsequently, based on the same database, Coppola et al. used bioinformatics analysis to further delineate key mediators involved in the astroglial-PNN-depression relationship and found important transcription factors in astroglial cells (Coppola et al., 2019). In addition to PNN, the serotonin system plays a critical role in the pathogenesis of stress, but therapies that target the stress and depression associated genes such as Tph2 and Slc6a4 (SERT) to modulate serotonin reuptake and degradation have no obvious effect in clinical trials (Lalovic and Turecki, 2002; Bellivier et al., 2004; Oquendo et al., 2014). Directly targeting serotonin signaling is expected to be an alternative therapeutic. A study of immunoprecipitated mRNAs associated with ribosome of serotonin neurons in ePet$\mathrm{Cre}^{\mathrm{tg} /-} / \mathrm{RiboTag}^{\mathrm{tg} /} /-$ mice (Scott et al., 2005) with conservative sequencing analysis showed that Fkbp5 mRNA translation decreased in the dorsal raphe brain region after repeated forced swims (Lesiak et al., 2020). The results not only support previous findings linking FKBP5 to depression, but also provide the first evidence linking FKBP5 to serotonin. Translatomics connects the three, and FKBP5 inhibitors are shown to have promise as potent and novel antidepressant treatments.

\section{Fragile X Syndrome}

Fragile $\mathrm{X}$ syndrome is a neuro-developmental and monogenic disease associated with autism spectrum disorder (ASD). FXS results from the loss of FMRP encoded by fragile X mental retardation 1 (FMR1). FMRP, a polyribosome-associated RNA binding protein, has always been thought to be involved in translational repression and in the maintenance of tuned protein synthesis, but there has been little consensus regarding the translational mechanism causing FXS before the use of translatomics. A study by Darnell et al. using crosslinking immunoprecipitation (HITS-CLIP) and polysome profiling to assess correspondence between FMRP and mouse brain-specific polyribosomal mRNAs, uncovered its role as a ribosomal brake, and showed that loss of the translational brake contributed to FXS (Darnell et al., 2011). However, stalled and active ribosomes move to the high sucrose concentration fraction during sucrose gradient centrifugation, implying that polysome profiling does not provide a perfect demonstration of translational activity (Sivan et al., 2007). Similarly, the TRAP method immunoprecipitates all ribosome-bound mRNA, and thus cannot differentiate between stalled and active ribosomes. It is also unclear whether FMRP significantly represses both initiation and elongation. Ribosome profiling yields insufficient information on overall ribosome density and ribosome stalling on each gene at high resolution. Supporting evidence has come from studies that measured and compared ribosomal occupancy, positioning, and translation efficiency (TE) in Fmr1 knockout vs. wild-type mice. These studies uncovered widespread decline of translational pausing but no significant translation initiation changes in Fmrl knockout mice (Das Sharma et al., 2019). Translatomics, especially ribosome profiling, dissects the nature of FMRP-mediated translational regulation. However, ribosome profiling used by Sharma et al. may not distinguish between translocating and stalled ribosomes, suggesting that key events leading to FXS may be overlooked. To circumvent this issue, Shah et al. discovered inhibited elongation in Fmr1 knockout mice by virtue of reduced TE and increased protein level. In order to distinguish between transiting and stalled ribosomes, a modified procedure was used. After blocking initiation of all hippocampal-cortical slices, followed by translocation inhibition at different time points using cycloheximide, ribosome profiling was then used for sample analysis (Shah et al., 2020). This approach detects mRNA-specific ribosome translocation dynamics in the nervous system, which is a remarkable breakthrough.

\section{Neurodegenerative Diseases}

A range of neurodegenerative diseases such as Parkinson's disease (PD), Alzheimer's disease (AD), and multiple sclerosis (MS) are increasingly considered to have molecular mechanisms including protein aggregation (Ross and Poirier, 2004). Parkinson's disease (PD) is the second most prevalent neurodegenerative disorder, with motor and non-motor symptoms (Samii et al., 2004). The most common genetic cause of Parkinson's disease is mutations in the LRRK2 gene. Kim et al. estimated translation efficiency by comparing between the ribosomeprofiling and the RNA-seq expression changes, and translational landscape demonstrated a global shift in G2019S LRRK2 human dopamine neurons (Kim et al., 2020). Of note, differentially regulated genes had a common feature with complex secondary structure in the $5^{\prime}$ untranslated region (UTR), and Ingenuity Pathway Analysis (IPA) showed $\mathrm{Ca}^{2+}$ signaling, which indicated elevated intracellular calcium levels (Kim et al., 2020). Ribosome profiling associated dysregulated translation control with intracellular $\mathrm{Ca}^{2+}$ homeostasis imbalance in G2019S 
LRRK2 human dopamine neurons. Alzheimer's disease (AD) is the leading cause of dementia, characterized by regression of learning and memory. Thus, it is necessary to study the translational regulatory mechanisms that affect memory to inhibit the onset and progression of $\mathrm{AD}$. Although the importance of translational regulators in memory consolidation has been shown, our understanding of target genes under translational control in memory formation is limited by the lack of accurate ways of quantifying translation rate (CostaMattioli et al., 2005). Cho et al. analyzed translation efficiency through temporal ribosome profiling and transcriptome profiling of the mouse hippocampus during memory consolidation and identified 3 different types of translationally repressive gene regulations distributed in steady-state, early, and late-phase (Cho et al., 2015). However, Mathew et al. pointed out that the probable inclusion of choroid plexus mRNA in hippocampal samples used by Cho et al. needs to be considered before drawing conclusions. Regional differences may occur in the transcriptome of each cell type during neurodegeneration. Thus, isolation of neurons from entire brain tissue needs to be resolved (Cho et al., 2016; Mathew et al., 2016). Cre-LoxP recombination can successfully generate ribo-tag mice expressing tagged ribosomes in specific cell types. Using $C \times 3 \mathrm{cr} 1^{\mathrm{CreER} / \mathrm{CreER}}$; Rosa $26^{f_{s} T R A P / f_{s} T R A P}$ mice, it was found that the chronic environmental risk factor $\mathrm{Cu}$ exposure impaired cognition and increased the incidence of $\mathrm{AD}$ by shifting microglia toward inflammatory phenotypes at translational levels (Lim et al., 2020). For multiple sclerosis (MS), another neurological degenerative disease, Olig1-RiboTag mice permit isolation of oligodendrocyte lineage cells, and allow specific translatomics in vivo from targeted regions during the remyelination phase of a MS model, and discovery of gene-expression pathways intrinsic to oligodendrocytes with MS (Voskuhl et al., 2019). Accurately interfering with the translation mechanism in specific cells of targeted regions may be novel therapeutic targets for neurodegenerative diseases.

The brain contains a diverse population of projection neurons with anatomical and molecular heterogeneity. Dissociating each projection neuron by laser-capture microdissection leads to the loss of RNA pools located in dendrites and axons, which account for $>50 \%$ of the neuronal volume (Tóth et al., 2018). Furthermore, cell isolation protocols are relatively inefficient, while TRAP has sufficient power to simultaneously analyze hundreds of cells for a candidate cell type (Huang et al., 2019). Although ribo-tag mice constructed with cre-loxp recombination have promoted the investigation of translation regulation on memory consolidation in cell types of specific brain regions, more specific spatial translational regulation such as axon-translation achieved by viral-TRAP could provide new insights into memory formation in projection neurons. Ostroff et al. injected retrograde virus into cortical area TE3 to express tagged Rpl10a (ribosomal protein L10a) at axon terminals, resulting in tagged Rpl10a expression in retrogradely transduced projection neurons of the amygdala region (Ostroff et al., 2019). Combined with RNA-seq, genome-wide biomolecular profiling of anatomically defined projective neurons can be performed. Ostroff et al. using viral-TRAP not only proved the recent assumption that axonal translation also occurs in the CNS neurons in vivo, but also demonstrated that axonal translation in projection regions is associated with memory formation. In addition to these viruses, which do not cross synapses, transsynaptic viruses may trace inputs farther upstream. Canine adenovirus type 2 - green fluorescent protein (CAV - GFP), a transsynaptic virus, was injected into particular brain regions including the nucleus accumbens shell, of transgenic mice whose ribosomal proteins fused with anti - GFP camelid nanobody, and was used to molecularly profile neurons projecting to farther regions (Ekstrand et al., 2014).

\section{Potential Applications of Translatomics in Neurological Diseases Alternative Transcript Isoforms}

The nervous system exhibits the most divergent and extensive use of alternative transcription isoforms, which may influence development of genetically-defined neuron types, neuronal maturation, and synapse specification (Furlanis and Scheiffele, 2018). Splicing misregulation is involved in the development and maintenance of neurologic diseases (Licatalosi and Darnell, 2006). High-throughput RNA-seq of autistic brains has identified a large number of downregulated alternative splicing of neuronal activity-dependent exons (Parikshak et al., 2016; QuesnelVallières et al., 2016). However, it is not clear to what extent transcription isoforms detected by RNA-seq are indeed translated into functional protein isoforms (Weatheritt et al., 2016; Tress et al., 2017). In addition to arising from transcription isoforms, protein isoforms may arise from same transcript encoding multiple protein variants via alternative translation initiation sites and termination sites. Although translatomics has not been used to explore whether the process of transcription isoforms to protein isoforms also plays an important role in neurological diseases such as autism, the possible mechanism of protein isoform production by translatomics in nervous cells has been studied (see below). This could lead to further study of diverse protein isoforms in neurological diseases.

As opposed to ribosome profiling in which only the coding sequence protected by ribosomes is detected, polysome profiling and TRAP can detect full-length translated mRNAs, including untranslated regions. Wong et al. used polysome profiling to investigate differential translation rates as quantified by shifts in ribosomal load between variant mRNA isoforms with alternate $5^{\prime}$ UTRs in embryonic stem cells-derived neural precursor cells (Wong et al., 2016). Furlanis et al. used TRAP to probe transcript isoforms that are recruited for translation across distinct neuron types (Furlanis et al., 2019). TRAP minimizes low-level background noise from widely expressed non-neuronal genes and facilitates detection of divergent alternative splicing programs across closely-related cell types. These two methods offer new possibilities to study contexts in which transcript isoforms are not completely translated into alternative splicing proteins. Ribosome profiling with codon resolution was used by Sapkota et al. to uncover novel translation initiation sites in the same transcript, which give rise to $\mathrm{N}$-terminal protein variants, and to identify new C-terminal extensions mediated by stop codon readthrough in neuron-glia cultures (Sapkota et al., 2019). 
Moreover, this study coupled TRAP to ribosome footprints for specific cell type analysis of translational readthrough in vivo. Taken together, the three translatomics methods have greatly enhanced our knowledge on diversity of protein isoforms.

\section{Novel Neuropeptides}

As signaling molecules and key mediators, brain-derived peptides are responsible for brain activities, including learning, memory, and stress (Borbély et al., 2013; Fazzari et al., 2018). Most reported neuropeptides to date are characterized as ligands for G-protein coupled receptors (GPCRs), which serve as extraordinarily efficient drug targets in general (O'Brien et al., 2019; Li et al., 2020). Given their therapeutic potential, significant efforts have been made to search for novel functional peptides in basic neuroscience. Currently, micropeptides from the brain are receiving more attention in translational neuroscience. However, the low abundance and atypical fragmentation of brain-derived peptides limits the effectiveness of conventional proteomics. The position of ribosomes and protected footprints by ribosome profiling facilitate identification of translation products and discovery of novel protein products. The combination of ribosome profiling and mass spectrometry may facilitate their detection in the brain (Tharakan et al., 2020). Moreover, the ribosome footprint distribution can identify translated upstream open reading frames (uORFs) (Jiang et al., 2017) and novel translation initiation or termination sites (Sapkota et al., 2019), providing clues for the discovery of novel micropeptides.

\section{Single mRNA Molecule Translation}

While the above-mentioned translatomics methods including polysome profiling, ribosomal profiling, and TRAP-seq have provided quantitative new insights for translation regulation in vivo, genome-wide methods require averaging of many mRNA molecules in cells, ignoring differences between individual mRNAs. To visualize translation dynamics of single mRNAs in living cells, Halstead et al. first developed a technique called translating RNA imaging by coat protein knock-off (TRICK) (Halstead et al., 2015), in which orthogonal bacteriophage PP7 and MS2 stem-loops were used to label a transcript with distinct fluorescent proteins. The PP7 capsid protein was fused with green fluorescent protein (PCP-GFP), and the MS2 capsid protein was fused to red fluorescent protein (MCP-RFP). Untranslated mRNAs simultaneously express green and red fluorescent proteins, while in contrast translated mRNAs which are at least undergoing the first round of translation are only labeled with MCP-RFP in the $3^{\prime}$ UTR. However, the TRICK technique is more suitable for detecting the first round of mRNA translation in living cells. A method based on the recently developed SunTag fluorescence labeling system to label nascent polypeptides of mRNA was described (Morisaki et al., 2016; Wang et al., 2016; Wu et al., 2016; Yan et al., 2016). In this method, the MS2 and PP7 systems (Halstead et al., 2015) are used to image mRNA to obtain the quantitative and positional relationship between mRNAs and the ribosome. Only one labeled polypeptide can be detected when using a fluorescence labeling system alone. Boersma et al. applied two independent MoonTag and SunTag systems with different fluorescent proteins, so the spatial-temporal translation of two different mRNAs can be observed in living cells (Boersma et al., 2019). Furthermore, the combined MoonTag and SunTag systems can image stop codon readthrough of single mRNAs by putting MoonTag in the open reading frame of the gene and SunTag after the stop codon (Boersma et al., 2019).

Few studies have achieved image translation of single mRNA molecules in living neurons. These found that translation was repressed in distal dendrites of primary neurons because $\sim 40 \%$ mRNAs were translated in proximal dendrites, but only $\sim 10 \%$ mRNAs were translated in distal dendrites (Wang et al., 2016; $\mathrm{Wu}$ et al., 2016). The bursting translation behavior of these mRNAs can effectively control the level and location of protein in synapses. This method is thus very important to explore the pathogenesis of mental disorders with synapse impairments such as fragile $\mathrm{X}$ chromosome syndrome (Blanco-Suárez et al., 2017). More experiments may be needed to verify and study the translation changes of a single mRNA molecule in nervous system diseases.

\section{Applications of Translatomics in Other Fields}

Translating ribosome affinity purification has many applications in the nervous system with multiple cells. In the nervous system cells, gene translation plays a prominent role in synaptic function (Sossin and Costa-Mattioli, 2019). Polysome profiling, a traditional method for analyzing RNC-mRNAs, can be traced back to the last century. Numerous studies have explored the regulation of gene translation by polysome profiling in vivo. Of note, in addition to obtaining RNCmRNAs that has been following, polysome profiling and TRAP can also be utilized to isolate ribosome-association protein complexes that are immunoprecipitated from gradient fractions or purified polysome-associated mRNA transcripts. The physiological functions of such protein complexes can be determined by western blotting or mass-spectrometry (Gandin et al., 2013; Simsek et al., 2017). One shortcoming of polysome profiling is that the slow gradient fraction and translation ribosome affinity purification method results in dissociation of tightly bound proteins and hence does not isolate proteins which interact transiently with ribosomes.

Initiation and advancement of translatomics guided by ribosome profiling revealed that some putative long non-coding RNAs (lncRNA) (Lu et al., 2019), microRNAs (Lauressergues et al., 2015) and circular RNAs (Ye et al., 2019) were misannotated as non-coding RNAs. Short open reading frames (sORF) contained in non-coding RNAs are ignored because do their small size (Figure 3). Micropeptides and proteins encoded by non-coding RNAs have been implicated in a variety of biological processes, such as embryonic development (Pauli et al., 2015), muscle function (Anderson et al., 2015), glioma cell suppression (Zhang M. et al., 2018; Wang J. et al., 2019), cell division (Handler et al., 2008) and morphogenesis (Kondo et al., 2007). In addition to non-coding RNAs, new translation patterns related to known coding genes have attracted much research attention. A significant portion of ribosome footprints outside of typical protein coding regions (CDSs) derive from the sequence of 5 


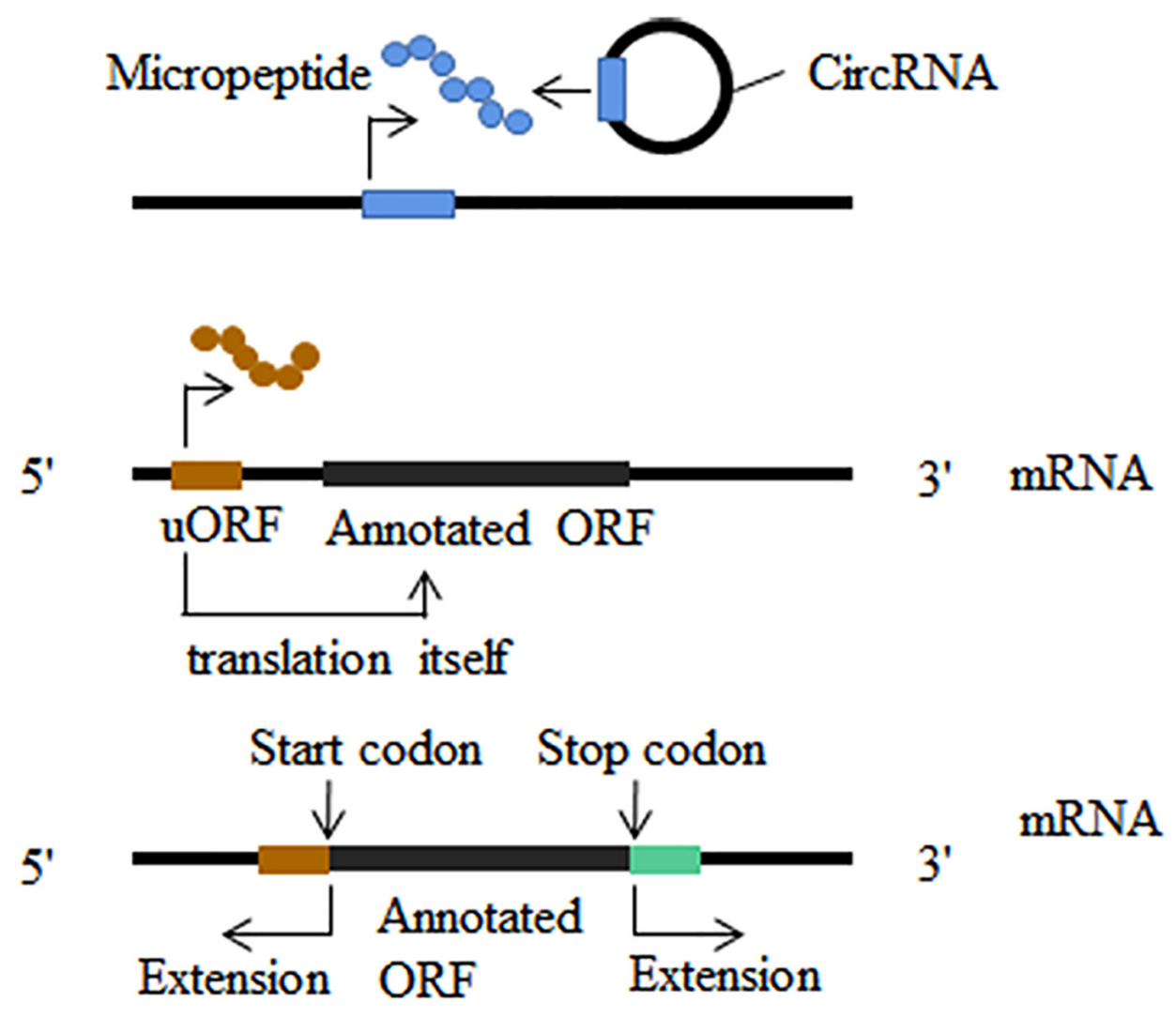

FIGURE 3 | Translatome analysis in other fields. New translatable molecule: non-coding RNAs are found to contain short open reading frames (sORF); upstream open reading frames (UORF) could translate into micropeptides and this translation can influence the translation of the downstream main open reading frames; stop-codon read-through and alternative translation extends in both $3^{\prime}$ and $5^{\prime}$ direction.

'UTR (Brar et al., 2012; Archer et al., 2016; Murat et al., 2018). Both upstream translation itself and micropeptides encoded by uORF often result in the suppression of the translation of the downstream main open reading frame (Figure 3; Mueller and Hinnebusch, 1986; Vattem and Wek, 2004; Rahmani et al., 2009; Wethmar, 2014; Ebina et al., 2015). Another translation pattern is stop-codon read-through which we have described in the nervous system (Figure 3; von der Haar and Tuite, 2007; Jungreis et al., 2016; Li and Zhang, 2019). Ribosome profiling can also analyze frameshift mutations in the main open reading frame, although it has not been remarkably successful (Atkins et al., 2017).

In addition to the combined analysis with classical omics including transcriptomic and proteomics in the nervous system (Das Sharma et al., 2019; Lupinacci et al., 2019; Wang X. et al., 2019; Tharakan et al., 2020), translatomics can be used in conjunction with $\mathrm{m} 6 \mathrm{~A}$-seq to characterize the effect of $\mathrm{m} 6 \mathrm{~A}$ modification located in the coding region of mRNA on the translation efficiency (Jia et al., 2019; Mao et al., 2019).

\section{CONCLUSION AND PERSPECTIVES}

The translation of mRNA into protein is an important cellular process. Any significant changes in the translation components can profoundly affect the development of the nervous system, thereby causing neurological diseases. Translatomics methods have revolutionized our ability to monitor RNC-mRNAs in vivo and analyze the regulation of translation. The applications of polysome profiling, ribosome profiling, and TRAP-seq in neurological diseases are listed in Table 1. However, it is clear that better protocols with improved performance are needed for efficient analysis of small samples of nervous system specimens. Compared with the other two methods, ribosome profiling has more gaps in the nervous system. In the future, depending on the precise genomic positional information obtained by ribosome profiling, the stop-codon readthrough occurring in neurons or in glial cells can be used to explore modulating effects of micropeptides encoded by putative non-coding RNAs and uORF on the development of the nervous system. Notably, the method of observing translation of single mRNA molecules in live neurons is a powerful tool for study of translation regulation in neurological diseases. Various combinations of translatomics methods reflecting different aspects of translatome and new translatomics approaches such as RNC-seq and TCP-seq would be useful in neurology field. Application of different omics data types can elucidate potential causative changes that lead to 
neurological disorders, which is essential for the design of precise and personalized medicine (Hasin et al., 2017). The translatome, an upgraded version of transcriptome, which couples with other omics such as genomics, metabolomics and microbiomics, is likely to promote development of translatomics in the study of the nervous system.

\section{AUTHOR CONTRIBUTIONS}

SZ conceived and wrote the manuscript. YC modified and reviewed the manuscript. YW, GC, PZ, and $\mathrm{YZ}$ edited the

\section{REFERENCES}

Aguilar-Valles, A., Haji, N., De Gregorio, D., Matta-Camacho, E., Eslamizade, M. J., Popic, J., et al. (2018). Translational control of depression-like behavior via phosphorylation of eukaryotic translation initiation factor 4E. Nat. Commun. 9:2459. doi: 10.1038/s41467-018-04883-5

Amorim, I. S., Kedia, S., Kouloulia, S., Simbriger, K., Gantois, I., Jafarnejad, S. M., et al. (2018). Loss of eIF4E phosphorylation engenders depression-like behaviors via selective mRNA translation. J. Neurosci. 38, 2118-2133. doi: 10. 1523/JNEUROSCI.2673-17.2018

Anderson, D. M., Anderson, K. M., Chang, C.-L., Makarewich, C. A., Nelson, B. R., McAnally, J. R., et al. (2015). A micropeptide encoded by a putative long noncoding RNA regulates muscle performance. Cell 160, 595-606. doi: 10.1016/j.cell.2015.01.009

Archer, S. K., Shirokikh, N. E., Beilharz, T. H., and Preiss, T. (2016). Dynamics of ribosome scanning and recycling revealed by translation complex profiling. Nature 535, 570-574.

Atkins, J. F., Loughran, G., and Baranov, P. V. (2017). A [Cu]rious ribosomal profiling pattern leads to the discovery of ribosomal frameshifting in the synthesis of a copper chaperone. Mol. Cell 65, 203-204. doi: 10.1016/j.molcel. 2017.01.002

Banasr, M., and Duman, R. S. (2008). Glial loss in the prefrontal cortex is sufficient to induce depressive-like behaviors. Biol. Psychiatry $64,863-870$. doi: 10.1016/j. biopsych.2008.06.008

Bayin, N. S., Modrek, A. S., and Placantonakis, D. G. (2014). Glioblastoma stem cells: molecular characteristics and therapeutic implications. World J. Stem Cells 6, 230-238. doi: 10.4252/wjsc.v6.i2.230

Beckelman, B. C., Zhou, X., Keene, C. D., and Ma, T. (2016). Impaired eukaryotic elongation factor $1 \mathrm{~A}$ expression in Alzheimer's Disease. Neuro Degenerative Dis. 16, 39-43. doi: $10.1159 / 000438925$

Bell, J. B., Eckerdt, F., Dhruv, H. D., Finlay, D., Peng, S., Kim, S., et al. (2018). Differential response of glioma stem cells to arsenic trioxide therapy is regulated by MNK1 and mRNA translation. Mol. Cancer Res. 16, 32-46. doi: 10.1158/ 1541-7786.MCR-17-0397

Bell, J. B., Eckerdt, F. D., Alley, K., Magnusson, L. P., Hussain, H., Bi, Y., et al. (2016). MNK inhibition disrupts mesenchymal glioma stem cells and prolongs survival in a mouse model of glioblastoma. Mol. Cancer Res. 14, 984-993.

Bellivier, F., Chaste, P., and Malafosse, A. (2004). Association between the TPH gene A218C polymorphism and suicidal behavior: a meta-analysis. Am. J. Med. Genet.Part B Neuropsychiatr. Genet. 124B, 87-91.

Bernabò, P., Tebaldi, T., Groen, E. J. N., Lane, F. M., Perenthaler, E., Mattedi, F., et al. (2017). In vivo translatome profiling in spinal muscular atrophy reveals a role for SMN protein in ribosome biology. Cell Rep. 21, 953-965. doi: 10.1016/j.celrep.2017.10.010

Biever, A., Glock, C., Tushev, G., Ciirdaeva, E., Dalmay, T., Langer, J. D., et al. (2020). Monosomes actively translate synaptic mRNAs in neuronal processes. Science 367:eaay4991. doi: 10.1126/science.aay4991

Blanco, S., Dietmann, S., Flores, J. V., Hussain, S., Kutter, C., Humphreys, P., et al. (2014). Aberrant methylation of tRNAs links cellular stress to neuro-developmental disorders. EMBO J. 33, 2020-2039. doi: 10.15252/embj. 201489282 manuscript. All authors contributed to the article and approved the submitted version.

\section{FUNDING}

This study was supported by grants from the National Natural Science Foundation of China (Nos. 81371214 and 81671063), the Natural Science Foundation of Zhejiang, China (No. LY16H090008), the Key Program of the Natural Science Foundation of Zhejiang, China (No. LZ19H090003), and Zhejiang Provincial Natural Science Foundation of China (No. LQ19H030009).

Blanco-Suárez, E., Caldwell, A. L. M., and Allen, N. J. (2017). Role of astrocytesynapse interactions in CNS disorders. J. Physiol. 595, 1903-1916. doi: 10.1113/ JP270988

Boersma, S., Khuperkar, D., Verhagen, B. M. P., Sonneveld, S., Grimm, J. B., Lavis, L. D., et al. (2019). Multi-color single-molecule imaging uncovers extensive heterogeneity in mRNA decoding. Cell 178, 458.e19-472.e19. doi: 10.1016/j.cell. 2019.05.001

Borbély, E., Scheich, B., and Helyes, Z. (2013). Neuropeptides in learning and memory. Neuropeptides 47, 439-450. doi: 10.1016/j.npep.2013.10.012

Brar, G. A., and Weissman, J. S. (2015). Ribosome profiling reveals the what, when, where and how of protein synthesis. Nat. Rev. Mol. Cell Biol. 16, 651-664. doi: 10.1038/nrm4069

Brar, G. A., Yassour, M., Friedman, N., Regev, A., Ingolia, N. T., and Weissman, J. S. (2012). High-resolution view of the yeast meiotic program revealed by ribosome profiling. Science 335, 552-557. doi: 10.1126/science.1215110

Chen, E., Sharma, M. R., Shi, X., Agrawal, R. K., and Joseph, S. (2014). Fragile $\mathrm{X}$ mental retardation protein regulates translation by binding directly to the ribosome. Mol. Cell 54, 407-417. doi: 10.1016/j.molcel.2014.03.023

Chen, Y.-J., Chen, C.-Y., Mai, T.-L., Chuang, C.-F., Chen, Y.-C., Gupta, S. K., et al. (2020). Genome-wide, integrative analysis of circular RNA dysregulation and the corresponding circular RNA-microRNA-mRNA regulatory axes in autism. Genome Res. 30, 375-391. doi: 10.1101/gr.255463.119

Cho, J., Yu, N.-K., Choi, J.-H., Sim, S.-E., Kang, S. J., Kwak, C., et al. (2015). Multiple repressive mechanisms in the hippocampus during memory formation. Science 350, 82-87. doi: 10.1126/science.aac7368

Cho, J., Yu, N.-K., Kim, V. N., and Kaang, B.-K. (2016). Response to comment on "Multiple repressive mechanisms in the hippocampus during memory formation". Science 353:453.

Colloca, L., Ludman, T., Bouhassira, D., Baron, R., Dickenson, A. H., Yarnitsky, D., et al. (2017). Neuropathic pain. Nat. Rev.Dis. Primers 3:17002. doi: 10.1038/ nrdp. 2017.2

Coppola, G., Rurak, G. M., Simard, S., and Salmaso, N. (2019). A further analysis and commentary on: profiling changes in cortical astroglial cells following chronic Stress. J. Exp. Neurosci. 13:1179069519870182. doi: 10.1177/ 1179069519870182

Costa-Mattioli, M., Gobert, D., Harding, H., Herdy, B., Azzi, M., Bruno, M., et al. (2005). Translational control of hippocampal synaptic plasticity and memory by the eIF2alpha kinase GCN2. Nature 436, 1166-1173.

Cozen, A. E., Quartley, E., Holmes, A. D., Hrabeta-Robinson, E., Phizicky, E. M., and Lowe, T. M. (2015). ARM-seq: AlkB-facilitated RNA methylation sequencing reveals a complex landscape of modified tRNA fragments. Nat. Methods 12, 879-884. doi: 10.1038/nmeth.3508

D’Amico, D., Mottis, A., Potenza, F., Sorrentino, V., Li, H., Romani, M., et al. (2019). The RNA-binding protein PUM2 impairs mitochondrial dynamics and mitophagy during aging. Mol. Cell 73, 775.e10-787.e10. doi: 10.1016/j.molcel. 2018.11.034

Dang, S., Feng, S., Tien, J., Peters, C. J., Bulkley, D., Lolicato, M., et al. (2017). CryoEM structures of the TMEM16A calcium-activated chloride channel. Nature 552, 426-429. doi: 10.1038/nature25024

Daniele, S., Giacomelli, C., and Martini, C. (2018). Brain ageing and neurodegenerative disease: The role of cellular waste management. Biochem. Pharmacol. 158, 207-216. doi: 10.1016/j.bcp.2018.10.030 
Darnell, J. C. (2014). Molecular biology. Ribosome rescue and neurodegeneration. Science 345, 378-379. doi: 10.1126/science. 1257193

Darnell, J. C., Van Driesche, S. J., Zhang, C., Hung, K. Y. S., Mele, A., Fraser, C. E., et al. (2011). FMRP stalls ribosomal translocation on mRNAs linked to synaptic function and autism. Cell 146, 247-261. doi: 10.1016/j.cell.2011.06.013

Das Sharma, S., Metz, J. B., Li, H., Hobson, B. D., Hornstein, N., Sulzer, D., et al. (2019). Widespread alterations in translation elongation in the brain of juvenile Fmr1 knockout mice. Cell Rep. 26, 3313.e5-3322.e5. doi: 10.1016/j.celrep.2019. 02.086

Donega, V., Burm, S. M., van Strien, M. E., van Bodegraven, E. J., Paliukhovich, I., Geut, H., et al. (2019). Transcriptome and proteome profiling of neural stem cells from the human subventricular zone in Parkinson's disease. Acta Neuropathol. Commun. 7:84. doi: 10.1186/s40478-019-0736-0

Doyle, J. P., Dougherty, J. D., Heiman, M., Schmidt, E. F., Stevens, T. R., Ma, G., et al. (2008). Application of a translational profiling approach for the comparative analysis of CNS cell types. Cell 135, 749-762. doi: 10.1016/j.cell. 2008.10.029

Drysdale, J. W., and Munro, H. N. (1967). Polysome profiles obtained from mammalian tissues by an improved procedure. Biochim. Biophys. Acta 138, 616-618.

Ebina, I., Takemoto-Tsutsumi, M., Watanabe, S., Koyama, H., Endo, Y., Kimata, K., et al. (2015). Identification of novel Arabidopsis thaliana upstream open reading frames that control expression of the main coding sequences in a peptide sequence-dependent manner. Nucleic Acids Res. 43, 1562-1576. doi: 10.1093/nar/gkv018

Ekstrand, M. I., Nectow, A. R., Knight, Z. A., Latcha, K. N., Pomeranz, L. E., and Friedman, J. M. (2014). Molecular profiling of neurons based on connectivity. Cell 157, 1230-1242. doi: 10.1016/j.cell.2014.03.059

Evans, M. E., Clark, W. C., Zheng, G., and Pan, T. (2017). Determination of tRNA aminoacylation levels by high-throughput sequencing. Nucleic Acids Res. 45:e133. doi: 10.1093/nar/gkx514

Fazzari, G., Zizza, M., Di Vito, A., Alò, R., Mele, M., Bruno, R., et al. (2018). Reduced learning and memory performances in high-fat treated hamsters related to brain neurotensin receptor1 expression variations. Behav. Brain Res. 347, 227-233. doi: 10.1016/j.bbr.2018.03.015

Filippi, M., Bar-Or, A., Piehl, F., Preziosa, P., Solari, A., Vukusic, S., et al. (2018). Multiple sclerosis. Nat. Rev.Dis. Primers 4:43. doi: 10.1038/s41572-018-0041-4

Floriou-Servou, A., von Ziegler, L., Stalder, L., Sturman, O., Privitera, M., Rassi, A., et al. (2018). distinct proteomic, transcriptomic, and epigenetic stress responses in dorsal and ventral hippocampus. Biol. Psychiatry 84, 531-541. doi: 10.1016/j. biopsych.2018.02.003

Furlanis, E., and Scheiffele, P. (2018). Regulation of neuronal differentiation, function, and plasticity by alternative splicing. Annu. Rev. Cell Dev. Biol. 34, 451-469. doi: 10.1146/annurev-cellbio-100617-062826

Furlanis, E., Traunmüller, L., Fucile, G., and Scheiffele, P. (2019). Landscape of ribosome-engaged transcript isoforms reveals extensive neuronal-cell-classspecific alternative splicing programs. Nat. Neurosci. 22, 1709-1717. doi: 10. 1038/s41593-019-0465-5

Gandin, V., Gutierrez, G. J., Brill, L. M., Varsano, T., Feng, Y., Aza-Blanc, P., et al. (2013). Degradation of newly synthesized polypeptides by ribosome-associated RACK1/c-Jun N-terminal kinase/eukaryotic elongation factor 1A2 complex. Mol. Cell. Biol. 33, 2510-2526. doi: 10.1128/MCB.01362-12

Gandin, V., Sikström, K., Alain, T., Morita, M., McLaughlan, S., Larsson, O., et al. (2014). Polysome fractionation and analysis of mammalian translatomes on a genome-wide scale. J. Vis. Exp. 17:51455. doi: 10.3791/51455

Gerashchenko, M. V., and Gladyshev, V. N. (2017). Ribonuclease selection for ribosome profiling. Nucleic Acids Res. 45:e6. doi: 10.1093/nar/gkw822

Germany, E. M., Zahayko, N., and Khalimonchuk, O. (2019). Isolation of Specific neuron populations from roundworm Caenorhabditis elegans. J. Vis. Exp. 6:10.3791/60145. doi: 10.3791/60145

Glock, C., Heumüller, M., and Schuman, E. M. (2017). mRNA transport \& local translation in neurons. Curr. Opin. Neurobiol. 45, 169-177. doi: 10.1016/j.conb. 2017.05.005

Greenbaum, D., Colangelo, C., Williams, K., and Gerstein, M. (2003). Comparing protein abundance and mRNA expression levels on a genomic scale. Genome Biol. 4:117.

Guttman, M., Russell, P., Ingolia, N. T., Weissman, J. S., and Lander, E. S. (2013). Ribosome profiling provides evidence that large noncoding
RNAs do not encode proteins. Cell 154, 240-251. doi: 10.1016/j.cell.2013. 06.009

Gygi, S. P., Rochon, Y., Franza, B. R., and Aebersold, R. (1999). Correlation between protein and mRNA abundance in yeast. Mol. Cell. Biol. 19, 1720-1730.

Hagerman, R. J., Berry-Kravis, E., Hazlett, H. C., Bailey, D. B., Moine, H., Kooy, R. F., et al. (2017). Fragile X syndrome. Nat. Rev. Dis. Primers 3:17065. doi: $10.1038 /$ nrdp.2017.65

Haimon, Z., Volaski, A., Orthgiess, J., Boura-Halfon, S., Varol, D., Shemer, A., et al. (2018). Re-evaluating microglia expression profiles using RiboTag and cell isolation strategies. Nat. Immunol. 19, 636-644. doi: 10.1038/s41590-0180110-6

Halstead, J. M., Lionnet, T., Wilbertz, J. H., Wippich, F., Ephrussi, A., Singer, R. H., et al. (2015). Translation. An RNA biosensor for imaging the first round of translation from single cells to living animals. Science 347, 1367-1671. doi: $10.1126 /$ science.aaa3380

Handler, A. A., Lim, J. E., and Losick, R. (2008). Peptide inhibitor of cytokinesis during sporulation in Bacillus subtilis. Mol. Microbiol. 68, 588-599. doi: 10. 1111/j.1365-2958.2008.06173.x

Hasin, Y., Seldin, M., and Lusis, A. (2017). Multi-omics approaches to disease. Genome Biol. 18:83. doi: 10.1186/s13059-017-1215-1

Heiman, M., Kulicke, R., Fenster, R. J., Greengard, P., and Heintz, N. (2014). Cell type-specific mRNA purification by translating ribosome affinity purification (TRAP). Nat. Protoc. 9, 1282-1291. doi: 10.1038/nprot.2014.085

Herrlinger, S., Shao, Q., Yang, M., Chang, Q., Liu, Y., Pan, X., et al. (2019). Lin28-mediated temporal promotion of protein synthesis is crucial for neural progenitor cell maintenance and brain development in mice. Development 146:dev173765. doi: 10.1242/dev.173765

Hirai, T., Mulpuri, Y., Cheng, Y., Xia, Z., Li, W., Ruangsri, S., et al. (2017). Aberrant plasticity of peripheral sensory axons in a painful neuropathy. Sci. Rep. 7:3407. doi: 10.1038/s41598-017-03390-9

Holt, C. E., Martin, K. C., and Schuman, E. M. (2019). Local translation in neurons: visualization and function. Nat. Struc. Mol. Biol. 26, 557-566. doi: 10.1038/ s41594-019-0263-5

Huang, T., Nguyen, L. H., Lin, T. V., Gong, X., Zhang, L., Kim, G. B., et al. (2019). In utero electroporation-based translating ribosome affinity purification identifies age-dependent mRNA expression in cortical pyramidal neurons. Neurosci. Res. 143, 44-52. doi: 10.1016/j.neures.2018.05.006

Inada, T., Winstall, E., Tarun, S. Z., Yates, J. R., Schieltz, D., and Sachs, A. B. (2002). One-step affinity purification of the yeast ribosome and its associated proteins and mRNAs. RNA 8, 948-958.

Ingolia, N. T., Brar, G. A., Rouskin, S., McGeachy, A. M., and Weissman, J. S. (2012). The ribosome profiling strategy for monitoring translation in vivo by deep sequencing of ribosome-protected mRNA fragments. Nat. Protoc. 7 , 1534-1550. doi: 10.1038/nprot.2012.086

Ingolia, N. T., Ghaemmaghami, S., Newman, J. R. S., and Weissman, J. S. (2009). Genome-wide analysis in vivo of translation with nucleotide resolution using ribosome profiling. Science 324, 218-223. doi: 10.1126/science.1168978

Ishimura, R., Nagy, G., Dotu, I., Zhou, H., Yang, X.-L., Schimmel, P., et al. (2014). RNA function. Ribosome stalling induced by mutation of a CNS-specific tRNA causes neurodegeneration. Science 345, 455-459. doi: 10.1126/science. 1249749

Ivanova, E. L., Mau-Them, F. T., Riazuddin, S., Kahrizi, K., Laugel, V., Schaefer, E., et al. (2017). Homozygous truncating variants in TBC1D23 cause pontocerebellar hypoplasia and alter cortical development. Am. J. Hum. Genet. 101, 428-440. doi: 10.1016/j.ajhg.2017.07.010

Jan, A., Jansonius, B., Delaidelli, A., Bhanshali, F., An, Y. A., Ferreira, N., et al. (2018). Activity of translation regulator eukaryotic elongation factor-2 kinase is increased in Parkinson disease brain and its inhibition reduces alpha synuclein toxicity. Acta Neuropathol. Commun. 6:54. doi: 10.1186/s40478-018-0554-9

Javed, A., Christodoulou, J., Cabrita, L. D., and Orlova, E. V. (2017). The ribosome and its role in protein folding: looking through a magnifying glass. Acta Crystallogr.Section D Struc. Biol. 73(Pt 6), 509-521. doi: 10.1107/ S2059798317007446

Jia, R., Chai, P., Wang, S., Sun, B., Xu, Y., Yang, Y., et al. (2019). mA modification suppresses ocular melanoma through modulating HINT2 mRNA translation. Mol. Cancer 18:161. doi: 10.1186/s12943-019-1088-x

Jiang, Z., Yang, J., Dai, A., Wang, Y., Li, W., and Xie, Z. (2017). Ribosome profiling reveals translational regulation of mammalian cells in response to hypoxic stress. BMC Genomics 18:638. doi: 10.1186/s12864-017-3996-8 
Jiménez-Díaz, L., Géranton, S. M., Passmore, G. M., Leith, J. L., Fisher, A. S., Berliocchi, L., et al. (2008). Local translation in primary afferent fibers regulates nociception. PLoS One 3:e1961. doi: 10.1371/journal.pone.0001961

Jungreis, I., Chan, C. S., Waterhouse, R. M., Fields, G., Lin, M. F., and Kellis, M. (2016). Evolutionary dynamics of abundant stop codon readthrough. Mol. Biol. Evol. 33, 3108-3132.

Kalinski, A. L., Sachdeva, R., Gomes, C., Lee, S. J., Shah, Z., Houle, J. D., et al. (2015). mRNAs and protein synthetic machinery localize into regenerating spinal cord axons when they are provided a substrate that supports growth. J. Neurosci. 35, 10357-10370. doi: 10.1523/JNEUROSCI.1249-15.2015

Kapur, M., Monaghan, C. E., and Ackerman, S. L. (2017). Regulation of mRNA translation in Neurons-A matter of life and death. Neuron 96, 616-637. doi: 10.1016/j.neuron.2017.09.057

Karaca, E., Weitzer, S., Pehlivan, D., Shiraishi, H., Gogakos, T., Hanada, T., et al. (2014). Human CLP1 mutations alter tRNA biogenesis, affecting both peripheral and central nervous system function. Cell 157, 636-650. doi: 10.1016/ j.cell.2014.02.058

Khoutorsky, A., and Price, T. J. (2018). Translational control mechanisms in persistent pain. Trends Neurosci. 41, 100-114. doi: 10.1016/j.tins.2017.11.006

Kim, J. W., Yin, X., Jhaldiyal, A., Khan, M. R., Martin, I., Xie, Z., et al. (2020). Defects in mRNA translation in LRRK2-Mutant hiPSC-derived dopaminergic neurons lead to dysregulated calcium homeostasis. Cell Stem Cell 27, 633.e7645.e7. doi: 10.1016/j.stem.2020.08.002

King, H. A., and Gerber, A. P. (2016). Translatome profiling: methods for genomescale analysis of mRNA translation. Briefings Funct. Genomics 15, 22-31. doi: 10.1093/bfgp/elu045

Kondo, T., Hashimoto, Y., Kato, K., Inagaki, S., Hayashi, S., and Kageyama, Y. (2007). Small peptide regulators of actin-based cell morphogenesis encoded by a polycistronic mRNA. Nat. Cell Biol. 9, 660-665.

Lalovic, A., and Turecki, G. (2002). Meta-analysis of the association between tryptophan hydroxylase and suicidal behavior. Am. J. Med. Genet. 114, 533-540.

Lareau, L. F., Hite, D. H., Hogan, G. J., and Brown, P. O. (2014). Distinct stages of the translation elongation cycle revealed by sequencing ribosome-protected mRNA fragments. eLife 3:e01257. doi: 10.7554/eLife.01257

Lauressergues, D., Couzigou, J.-M., Clemente, H. S., Martinez, Y., Dunand, C., Bécard, G., et al. (2015). Primary transcripts of microRNAs encode regulatory peptides. Nature 520, 90-93. doi: 10.1038/nature14346

Laverty, D., Desai, R., Uchański, T., Masiulis, S., Stec, W. J., Malinauskas, T., et al. (2019). Cryo-EM structure of the human $\alpha 1 \beta 3 \gamma 2$ GABA receptor in a lipid bilayer. Nature 565, 516-520. doi: 10.1038/s41586-018-0833-4

Lesiak, A. J., Coffey, K., Cohen, J. H., Liang, K. J., Chavkin, C., and Neumaier, J. F. (2020). Sequencing the serotonergic neuron translatome reveals a new role for Fkbp5 in stress. Mol. Psychiatry doi: 10.1038/s41380-020-0750-4 [Epub ahead of print].

Li, C., and Zhang, J. (2019). Stop-codon read-through arises largely from molecular errors and is generally nonadaptive. PLoS Genet. 15:e1008141. doi: 10.1371/ journal.pgen.1008141

Li, X., Du, L., Jiang, X.-J., Ju, Q., Qu, C.-J., Qu, M.-J., et al. (2020). Identification and characterization of neuropeptides and their g protein-coupled receptors (GPCRs) in the cowpea aphid. Front. Endocrinol. 11:640. doi: 10.3389/fendo. 2020.00640

Liang, S., Bellato, H. M., Lorent, J., Lupinacci, F. C. S., Oertlin, C., van Hoef, V., et al. (2018). Polysome-profiling in small tissue samples. Nucleic Acids Res. 46:e3. doi: 10.1093/nar/gkx940

Licatalosi, D. D., and Darnell, R. B. (2006). Splicing regulation in neurologic disease. Neuron 52, 93-101.

Lim, S. L., Rodriguez-Ortiz, C. J., Hsu, H.-W., Wu, J., Zumkehr, J., Kilian, J., et al. (2020). Chronic copper exposure directs microglia towards degenerative expression signatures in wild-type and J20 mouse model of Alzheimer's disease. J. Trace Elem. Med. Biol. 62:126578. doi: 10.1016/j.jtemb.2020.126578

Lin, S., Liu, Q., Lelyveld, V. S., Choe, J., Szostak, J. W., and Gregory, R. I. (2018). Mettl1/Wdr4-Mediated mG tRNA methylome is required for normal mRNA translation and embryonic stem cell self-renewal and differentiation. Mol. Cell 71, 244.e5-255.e5. doi: 10.1016/j.molcel.2018.06.001

Liu, S., Chang, S., Han, B., Xu, L., Zhang, M., Zhao, C., et al. (2019). Cryo-EM structures of the human cation-chloride cotransporter KCC1. Science 366, 505-508. doi: 10.1126/science.aay3129
Liu, W., Xiang, L., Zheng, T., Jin, J., and Zhang, G. (2018). TranslatomeDB: a comprehensive database and cloud-based analysis platform for translatome sequencing data. Nucleic Acids Res. 46, D206-D212. doi: 10.1093/nar/gkx1034

Liu, Y., Beyer, A., and Aebersold, R. (2016). On the dependency of cellular protein levels on mRNA abundance. Cell 165, 535-550. doi: 10.1016/j.cell.2016. 03.014

Lu, S., Zhang, J., Lian, X., Sun, L., Meng, K., Chen, Y., et al. (2019). A hidden human proteome encoded by 'non-coding' genes. Nucleic Acids Res. 47, 8111-8125. doi: 10.1093/nar/gkz646

Lupinacci, F. C. S., Kuasne, H., Roffé, M., Vassalakis, J. A., da Silva, F. F., Santos, T. G., et al. (2019). Polysome profiling of a human glioblastoma reveals intratumoral heterogeneity. Int. J. Mol. Sci. 20:2177. doi: 10.3390/ijms20092177

Mao, Y., Dong, L., Liu, X.-M., Guo, J., Ma, H., Shen, B., et al. (2019). mA in mRNA coding regions promotes translation via the RNA helicase-containing YTHDC2. Nat. Commun. 10:5332. doi: 10.1038/s41467-019-13317-9

Mathew, R. S., Mullan, H., Blusztajn, J. K., and Lehtinen, M. K. (2016). Comment on "Multiple repressive mechanisms in the hippocampus during memory formation". Science 353:453.

Megat, S., Ray, P. R., Moy, J. K., Lou, T.-F., Barragán-Iglesias, P., Li, Y., et al. (2019a). Nociceptor translational profiling reveals the ragulator-Rag GTPase complex as a critical generator of neuropathic pain. J. Neurosci. 39, 393-411. doi: 10.1523/JNEUROSCI.2661-18.2018

Megat, S., Ray, P. R., Tavares-Ferreira, D., Moy, J. K., Sankaranarayanan, I., Wanghzou, A., et al. (2019b). Differences between dorsal root and trigeminal ganglion nociceptors in mice revealed by translational profiling. J. Neurosci. 39, 6829-6847. doi: 10.1523/JNEUROSCI.2663-18.2019

Melemedjian, O. K., Asiedu, M. N., Tillu, D. V., Peebles, K. A., Yan, J., Ertz, N., et al. (2010). IL-6- and NGF-induced rapid control of protein synthesis and nociceptive plasticity via convergent signaling to the eIF4F complex. J. Neurosci. 30, 15113-15123. doi: 10.1523/JNEUROSCI.3947-10.2010

Melemedjian, O. K., Tillu, D. V., Moy, J. K., Asiedu, M. N., Mandell, E. K., Ghosh, S., et al. (2014). Local translation and retrograde axonal transport of CREB regulates IL-6-induced nociceptive plasticity. Mol. Pain 10:45. doi: 10.1186/ 1744-8069-10-45

Meyer-Schuman, R., and Antonellis, A. (2017). Emerging mechanisms of aminoacyl-tRNA synthetase mutations in recessive and dominant human disease. Hum. Mol. Genet. 26, R114-R127. doi: 10.1093/hmg/ddx231

Michel, A. M., Choudhury, K. R., Firth, A. E., Ingolia, N. T., Atkins, J. F., and Baranov, P. V. (2012). Observation of dually decoded regions of the human genome using ribosome profiling data. Genome Res. 22, 2219-2229. doi: 10. $1101 /$ gr.133249.111

Mills, E. W., and Green, R. (2017). Ribosomopathies: there's strength in numbers. Science 358:eaan2755. doi: 10.1126/science.aan2755

Morisaki, T., Lyon, K., DeLuca, K. F., DeLuca, J. G., English, B. P., Zhang, Z., et al. (2016). Real-time quantification of single RNA translation dynamics in living cells. Science 352, 1425-1429. doi: 10.1126/science.aaf0899

Mueller, P. P., and Hinnebusch, A. G. (1986). Multiple upstream AUG codons mediate translational control of GCN4. Cell 45, 201-207.

Murat, P., Marsico, G., Herdy, B., Ghanbarian, A. T., Portella, G., and Balasubramanian, S. (2018). RNA G-quadruplexes at upstream open reading frames cause DHX36- and DHX9-dependent translation of human mRNAs. Genome Biol. 19:229. doi: 10.1186/s13059-018-1602-2

Murphy, C. P., Li, X., Maurer, V., Oberhauser, M., Gstir, R., Wearick-Silva, L. E., et al. (2017). MicroRNA-mediated rescue of fear extinction memory by miR144-3p in extinction-impaired mice. Biol. Psychiatry 81, 979-989. doi: 10.1016/ j.biopsych.2016.12.021

Musier-Forsyth, K. (2019). Aminoacyl-tRNA synthetases and tRNAs in human disease: an introduction to the JBC reviews thematic series. J. Biol. Chem. 294, 5292-5293. doi: 10.1074/jbc.REV119.007721

Myasnikov, A. G., Kundhavai Natchiar, S., Nebout, M., Hazemann, I., Imbert, V., Khatter, H., et al. (2016). Structure-function insights reveal the human ribosome as a cancer target for antibiotics. Na. Commun. 7:12856. doi: 10.1038/ ncomms 12856

Nagy, C., Suderman, M., Yang, J., Szyf, M., Mechawar, N., Ernst, C., et al. (2015). Astrocytic abnormalities and global DNA methylation patterns in depression and suicide. Mol. Psychiatry 20, 320-328. doi: 10.1038/mp.2014.21

Nakano, I. (2015). Stem cell signature in glioblastoma: therapeutic development for a moving target. J. Neurosurg. 122, 324-330. doi: 10.3171/2014.9.JNS132253 
Neidermyer, W. J., and Whelan, S. P. J. (2019). Global analysis of polysomeassociated mRNA in vesicular stomatitis virus infected cells. PLoS Pathog. 15:e1007875. doi: 10.1371/journal.ppat.1007875

O’Brien, J. B., Wilkinson, J. C., and Roman, D. L. (2019). Regulator of G-protein signaling (RGS) proteins as drug targets: progress and future potentials. J. Biol. Chem. 294, 18571-18585. doi: 10.1074/jbc.REV119.007060

Ognjenović, J., and Simonović, M. (2018). Human aminoacyl-tRNA synthetases in diseases of the nervous system. RNA Biol. 15, 623-634. doi: 10.1080/15476286. 2017.1330245

Okada, S., Saiwai, H., Kumamaru, H., Kubota, K., Harada, A., Yamaguchi, M., et al. (2011). Flow cytometric sorting of neuronal and glial nuclei from central nervous system tissue. J. Cell. Physiol. 226, 552-558. doi: 10.1002/jcp. 22365

Oquendo, M. A., Sullivan, G. M., Sudol, K., Baca-Garcia, E., Stanley, B. H., Sublette, M. E., et al. (2014). Toward a biosignature for suicide. he Am. J. Psychiatry 171, 1259-1277. doi: 10.1176/appi.ajp.2014.14020194

Ostroff, L. E., Santini, E., Sears, R., Deane, Z., Kanadia, R. N., LeDoux, J. E., et al. (2019). Axon TRAP reveals learning-associated alterations in cortical axonal mRNAs in the lateral amgydala. eLife 8:e51607. doi: 10.7554/eLife.51607

Parikshak, N. N., Swarup, V., Belgard, T. G., Irimia, M., Ramaswami, G., Gandal, M. J., et al. (2016). Genome-wide changes in lncRNA, splicing, and regional gene expression patterns in autism. Nature 540, 423-427. doi: 10.1038/ nature 20612

Paulet, D., David, A., and Rivals, E. (2017). Ribo-seq enlightens codon usage bias. DNA Res. 24, 303-210. doi: 10.1093/dnares/dsw062

Pauli, A., Valen, E., and Schier, A. F. (2015). Identifying (non-)coding RNAs and small peptides: challenges and opportunities. BioEssays 37, 103-112. doi: 10. 1002/bies.201400103

Peña, C., Hurt, E., and Panse, V. G. (2017). Eukaryotic ribosome assembly, transport and quality control. Nat Struc. Mol. Biol. 24, 689-699. doi: 10.1038/ nsmb.3454

Peng, L., Verkhratsky, A., Gu, L., and Li, B. (2015). Targeting astrocytes in major depression. Expert Rev. Neurother. 15, 1299-1306. doi: 10.1586/14737175.2015. 1095094

Poewe, W., Seppi, K., Tanner, C. M., Halliday, G. M., Brundin, P., Volkmann, J., et al. (2017). Parkinson disease. Nat. Rev.Dis. Primers 3:17013. doi: 10.1038/ nrdp.2017.13

Quesnel-Vallières, M., Dargaei, Z., Irimia, M., Gonatopoulos-Pournatzis, T., Ip, J. Y., Wu, M., et al. (2016). Misregulation of an activity-dependent splicing network as a common mechanism underlying autism spectrum disorders. Mol. Cell 64, 1023-1034. doi: 10.1016/j.molcel.2016.11.033

Rahmani, F., Hummel, M., Schuurmans, J., Wiese-Klinkenberg, A., Smeekens, S., and Hanson, J. (2009). Sucrose control of translation mediated by an upstream open reading frame-encoded peptide. Plant Physiol. 150, 1356-1367. doi: 10. 1104/pp.109.136036

Ramos, J., and Fu, D. (2019). The emerging impact of tRNA modifications in the brain and nervous system. Biochim. Biophys. Acta Gene Regul. Mech. 1862, 412-428. doi: 10.1016/j.bbagrm.2018.11.007

Rangaraju, V., Tom Dieck, S., and Schuman, E. M. (2017). Local translation in neuronal compartments: how local is local? EMBO Rep. 18, 693-711. doi: 10. 15252/embr.201744045

Requião, R. D., Fernandes, L., de Souza, H. J. A., Rossetto, S., Domitrovic, T., and Palhano, F. L. (2017). Protein charge distribution in proteomes and its impact on translation. PLoS Comput. Biol. 13:e1005549. doi: 10.1371/journal. pcbi. 1005549

Rodnina, M. V. (2018). Translation in prokaryotes. Cold Spring Harbor Perspect. Biol. 10:a032664. doi: 10.1101/cshperspect.a032664

Rodriguez, C. M., Chun, S. Y., Mills, R. E., and Todd, P. K. (2019). Translation of upstream open reading frames in a model of neuronal differentiation. $B M C$ Genomics 20:391. doi: 10.1186/s12864-019-5775-1

Ross, C. A., and Poirier, M. A. (2004). Protein aggregation and neurodegenerative disease. Nat. Med. 10(Suppl.), S10-S17.

Rubio, F. J., Li, X., Liu, Q.-R., Cimbro, R., and Hope, B. T. (2016). Fluorescence activated cell sorting (FACS) and gene expression analysis of fos-expressing neurons from fresh and frozen rat brain tissue. J. Vis. Exp. 27:54358. doi: $10.3791 / 54358$

Samii, A., Nutt, J. G., and Ransom, B. R. (2004). Parkinson's disease. Lancet 363, 1783-1793.
Sapkota, D., Lake, A. M., Yang, W., Yang, C., Wesseling, H., Guise, A., et al. (2019). Cell-type-specific profiling of alternative translation identifies regulated protein isoform variation in the mouse brain. Cell Rep. 26, 594.e7-607.e7. doi: 10.1016/j.celrep.2018.12.077

Saunders, A., Macosko, E. Z., Wysoker, A., Goldman, M., Krienen, F. M., de Rivera, H., et al. (2018). Molecular diversity and specializations among the cells of the adult mouse brain. Cell 174, 1015.e16-1030.e16. doi: 10.1016/j.cell.2018. 07.028

Schaffer, A. E., Pinkard, O., and Coller, J. M. (2019). tRNA metabolism and neurodevelopmental disorders. Annu. Rev. Genomics Hum. Genet. 20, 359-387. doi: 10.1146/annurev-genom-083118-015334

Schmidt, K., Forkmann, K., Sinke, C., Gratz, M., Bitz, A., and Bingel, U. (2016). The differential effect of trigeminal vs. peripheral pain stimulation on visual processing and memory encoding is influenced by pain-related fear. NeuroImage 134, 386-395. doi: 10.1016/j.neuroimage.2016.03.026

Schratt, G. M., Tuebing, F., Nigh, E. A., Kane, C. G., Sabatini, M. E., Kiebler, M., et al. (2006). A brain-specific microRNA regulates dendritic spine development. Nature 439, 283-289.

Schwanhäusser, B., Busse, D., Li, N., Dittmar, G., Schuchhardt, J., Wolf, J., et al. (2011). Global quantification of mammalian gene expression control. Nature 473, 337-342. doi: 10.1038/nature10098

Scott, M. M., Wylie, C. J., Lerch, J. K., Murphy, R., Lobur, K., Herlitze, S., et al. (2005). A genetic approach to access serotonin neurons for in vivo and in vitro studies. Proc. Natl. Acad. Sci. U.S.A. 102, 16472-16477.

Shah, S., Molinaro, G., Liu, B., Wang, R., Huber, K. M., and Richter, J. D. (2020). FMRP control of ribosome translocation promotes chromatin modifications and alternative splicing of neuronal genes linked to autism. Cell Rep. 30, 4459-4472.e6. doi: 10.1016/j.celrep.2020.02.076

Sharma, K., Schmitt, S., Bergner, C. G., Tyanova, S., Kannaiyan, N., ManriqueHoyos, N., et al. (2015). Cell type- and brain region-resolved mouse brain proteome. Nat. Neurosci. 18, 1819-1831. doi: 10.1038/nn.4160

Shawahna, R., Uchida, Y., Declèves, X., Ohtsuki, S., Yousif, S., Dauchy, S., et al. (2011). Transcriptomic and quantitative proteomic analysis of transporters and drug metabolizing enzymes in freshly isolated human brain microvessels. Mol. Pharm. 8, 1332-1341. doi: 10.1021/mp200129p

Shigeoka, T., Jung, H., Jung, J., Turner-Bridger, B., Ohk, J., Lin, J. Q., et al. (2016). Dynamic axonal translation in developing and mature visual circuits. Cell 166, 181-192. doi: 10.1016/j.cell.2016.05.029

Simard, S., Coppola, G., Rudyk, C. A., Hayley, S., McQuaid, R. J., and Salmaso, N. (2018). Profiling changes in cortical astroglial cells following chronic stress. Neuropsychopharmacology 43, 1961-1971. doi: 10.1038/s41386-018-0105-x

Simsek, D., Tiu, G. C., Flynn, R. A., Byeon, G. W., Leppek, K., Xu, A. F., et al. (2017). The mammalian ribo-interactome reveals ribosome functional diversity and heterogeneity. Cell, 1051.e18-1065.e18. doi: 10.1016/j.cell.2017.05.022

Sivan, G., Kedersha, N., and Elroy-Stein, O. (2007). Ribosomal slowdown mediates translational arrest during cellular division. Mol. Cell. Biol. 27, 6639-6646.

Slomnicki, L. P., Hallgren, J., Vashishta, A., Smith, S. C., Ellis, S. R., and Hetman, M. (2018). Proapoptotic requirement of ribosomal protein L11 in ribosomal stresschallenged cortical neurons. Mol. Neurobiol. 55, 538-553. doi: 10.1007/s12035016-0336-y

Slomnicki, L. P., Malinowska, A., Kistowski, M., Palusinski, A., Zheng, J.-J., Sepp, M., et al. (2016). Nucleolar enrichment of brain proteins with critical roles in human neurodevelopment. Mol. Cell. Proteomics 15, 2055-2075. doi: 10.1074/ mcp.M115.051920

Smagin, D. A., Kovalenko, I. L., Galyamina, A. G., Bragin, A. O., Orlov, Y. L., and Kudryavtseva, N. N. (2016). Dysfunction in ribosomal gene expression in the hypothalamus and hippocampus following chronic social defeat stress in male mice as revealed by RNA-Seq. Neural Plasticity 2016:3289187. doi: $10.1155 / 2016 / 3289187$

Smith, K. (2014). Mental health: a world of depression. Nature 515:181. doi: 10. 1038/515180a

Sossin, W. S., and Costa-Mattioli, M. (2019). Translational control in the brain in health and disease. Cold Spring Harbor Perspect. Biol. 11:a032912. doi: 10.1101/ cshperspect.a032912

Spealman, P., Naik, A. W., May, G. E., Kuersten, S., Freeberg, L., Murphy, R. F., et al. (2018). Conserved non-AUG uORFs revealed by a novel regression analysis of ribosome profiling data. Genome Res. 28, 214-222. doi: 10.1101/gr. 221507.117 
Su, C.-H., D, D., and Tarn, W.-Y. (2018). Alternative splicing in neurogenesis and brain development. Front. Mol. Biosci. 5:12. doi: 10.3389/fmolb.2018. 00012

Thakor, D. K., Lin, A., Matsuka, Y., Meyer, E. M., Ruangsri, S., Nishimura, I., et al. (2009). Increased peripheral nerve excitability and local NaV1.8 mRNA up-regulation in painful neuropathy. Mol Pain 5:14. doi: 10.1186/1744-80 69-5-14

Tharakan, R., Kreimer, S., Ubaida-Mohien, C., Lavoie, J., Olexiouk, V., Menschaert, G., et al. (2020). A methodology for discovering novel brain-relevant peptides: combination of ribosome profiling and peptidomics. Neurosci. Res. 151, 31-37. doi: 10.1016/j.neures.2019.02.006

Tomlinson, J. E., Golshadi, M., Donahue, C. J., Dong, L., and Cheetham, J. (2020). Evaluation of two methods to isolate Schwann cells from murine sciatic nerve. J. Neurosci. Methods 331:108483. doi: 10.1016/j.jneumeth.2019.108483

Torres, A. G., Reina, O., Stephan-Otto Attolini, C., and de Pouplana, L. R. (2019). Differential expression of human tRNA genes drives the abundance of tRNAderived fragments. Proc. Natl. Acad. Sci. U.S.A. 116, 8451-8456. doi: 10.1073/ pnas. 1821120116

Tóth, E. N., Lohith, A., Mondal, M., Guo, J., Fukamizu, A., and Pourmand, N. (2018). Single-cell nanobiopsy reveals compartmentalization of mRNAs within neuronal cells. J. Biol. Chem. 293, 4940-4951. doi: 10.1074/jbc.M117.800763

Tress, M. L., Abascal, F., and Valencia, A. (2017). Alternative splicing may not be the key to proteome complexity. Trends Biochem. Sci. 42, 98-110. doi: 10.1016/ j.tibs.2016.08.008

Tsai, J. C., Miller-Vedam, L. E., Anand, A. A., Jaishankar, P., Nguyen, H. C., Renslo, A. R., et al. (2018). Structure of the nucleotide exchange factor eIF2B reveals mechanism of memory-enhancing molecule. Science 359:eaaq0939. doi: 10.1126/science.aaq0939

Uttam, S., Wong, C., Amorim, I. S., Jafarnejad, S. M., Tansley, S. N., Yang, J., et al. (2018a). Translational profiling of dorsal root ganglia and spinal cord in a mouse model of neuropathic pain. Neurobiol. Pain 4, 35-44. doi: 10.1016/j. ynpai.2018.04.001

Uttam, S., Wong, C., Price, T. J., and Khoutorsky, A. (2018b). eIF4E-dependent translational control: a central mechanism for regulation of pain plasticity. Front. Genet. 9:470. doi: 10.3389/fgene.2018.00470

Vattem, K. M., and Wek, R. C. (2004). Reinitiation involving upstream ORFs regulates ATF4 mRNA translation in mammalian cells. Proc. $t$ Natl. Acad. Sci. U.S A. 101, 11269-11274.

von der Haar, T., and Tuite, M. F. (2007). Regulated translational bypass of stop codons in yeast. Trends Microbiol. 15, 78-86.

von Loeffelholz, O., Natchiar, S. K., Djabeur, N., Myasnikov, A. G., Kratzat, H., Ménétret, J.-F., et al. (2017). Focused classification and refinement in highresolution cryo-EM structural analysis of ribosome complexes. Curr. Opin. Struc. Biol. 46, 140-148. doi: 10.1016/j.sbi.2017.07.007

Voskuhl, R. R., Itoh, N., Tassoni, A., Matsukawa, M. A., Ren, E., Tse, V., et al. (2019). Gene expression in oligodendrocytes during remyelination reveals cholesterol homeostasis as a therapeutic target in multiple sclerosis. Proc. Natl. Acad. Sci. U.S.A. 116, 10130-10139. doi: 10.1073/pnas.1821306116

Wahba, A., Rath, B. H., Bisht, K., Camphausen, K., and Tofilon, P. J. (2016). Polysome profiling links translational control to the radioresponse of glioblastoma stem-like cells. Cancer Res. 76, 3078-3087. doi: 10.1158/00085472.CAN-15-3050

Wahba, A., Rath, B. H., O’Neill, J. W., Camphausen, K., and Tofilon, P. J. (2018). The XPO1 inhibitor selinexor inhibits translation and enhances the radiosensitivity of glioblastoma cells grown and In Vitro and In Vivo. Mol. Cancer Ther. 17, 1717-1726. doi: 10.1158/1535-7163.MCT-17-1303

Wang, C., Han, B., Zhou, R., and Zhuang, X. (2016). Real-time imaging of translation on single mRNA transcripts in live cells. Cell 165, 990-1001. doi: 10.1016/j.cell.2016.04.040

Wang, J., Zhu, S., Meng, N., He, Y., Lu, R., and Yan, G.-R. (2019). ncRNA-encoded peptides or proteins and cancer. Mol. Ther. 27, 1718-1725. doi: 10.1016/j. ymthe.2019.09.001

Wang, X., You, X., Langer, J. D., Hou, J., Rupprecht, F., Vlatkovic, I., et al. (2019). Full-length transcriptome reconstruction reveals a large diversity of RNA and protein isoforms in rat hippocampus. Nat. Commun. 10:5009. doi: 10.1038/ s41467-019-13037-0

Wang, T., Cui, Y., Jin, J., Guo, J., Wang, G., Yin, X., et al. (2013). Translating mRNAs strongly correlate to proteins in a multivariate manner and their translation ratios are phenotype specific. Nucleic Acids Res. 41, 4743-4754. doi: $10.1093 /$ nar/gkt178

Wang, Z., Gerstein, M., and Snyder, M. (2009). RNA-Seq: a revolutionary tool for transcriptomics. Nat. Rev. Genet. 10, 57-63. doi: 10.1038/nrg2484

Weatheritt, R. J., Sterne-Weiler, T., and Blencowe, B. J. (2016). The ribosomeengaged landscape of alternative splicing. Nat. Struct. Mol. Biol. 23, 1117-1123. doi: $10.1038 / \mathrm{nsmb} .3317$

Westphal, M., and Lamszus, K. (2011). The neurobiology of gliomas: from cell biology to the development of therapeutic approaches. Nat. Rev.Neurosci. 12, 495-508. doi: 10.1038/nrn3060

Wethmar, K. (2014). The regulatory potential of upstream open reading frames in eukaryotic gene expression. Wiley Interdiscip. Rev. 5, 765-778. doi: 10.1002/ wrna. 1245

Wilson, D. N., and Doudna Cate, J. H. (2012). The structure and function of the eukaryotic ribosome. Cold Spring Harbor Perspect. Biol. 4:a011536. doi: 10.1101/cshperspect.a011536

Wong, Q. W.-L., Vaz, C., Lee, Q. Y., Zhao, T. Y., Luo, R., Archer, S. K., et al. (2016). Embryonic stem cells exhibit mRNA isoform specific translational regulation. PLoS One 11:e0143235. doi: 10.1371/journal.pone.0143235

Wu, B., Eliscovich, C., Yoon, Y. J., and Singer, R. H. (2016). Translation dynamics of single mRNAs in live cells and neurons. Science 352, 1430-1435. doi: 10.1126/ science.aaf1084

Wu, C. C.-C., Zinshteyn, B., Wehner, K. A., and Green, R. (2019). High-resolution ribosome profiling defines discrete ribosome elongation states and translational regulation during cellular stress. Mol. Cell 73, 959.e5-970.e5. doi: 10.1016/j. molcel.2018.12.009

Xue, S., and Barna, M. (2012). Specialized ribosomes: a new frontier in gene regulation and organismal biology. Nat Rev.Mol. Cell Biol. 13, 355-369. doi: $10.1038 / \mathrm{nrm} 3359$

Yan, X., Hoek, T. A., Vale, R. D., and Tanenbaum, M. E. (2016). Dynamics of translation of single mRNA molecules In Vivo. Cell 165, 976-989. doi: 10.1016/ j.cell.2016.04.034

Ye, F., Gao, G., Zou, Y., Zheng, S., Zhang, L., Ou, X., et al. (2019). circFBXW7 inhibits malignant progression by sponging miR-197-3p and Encoding a 185aa protein in triple-negative breast cancer. Mol. Ther. Nucleic Acids 18, 88-98. doi: 10.1016/j.omtn.2019.07.023

Zanni, G., Kalscheuer, V. M., Friedrich, A., Barresi, S., Alfieri, P., Di Capua, M., et al. (2015). A novel mutation in RPL10 (Ribosomal Protein L10) Causes $\mathrm{X}$-Linked intellectual disability, cerebellar hypoplasia, and spondylo-epiphyseal dysplasia. Hum. Mutat. 36, 1155-1158. doi: 10.1002/humu.22860

Zhang, H., Li, D., Zhang, Y., Li, J., Ma, S., Zhang, J., et al. (2018). Knockdown of IncRNA BDNF-AS suppresses neuronal cell apoptosis via downregulating miR-130b-5p target gene PRDM5 in acute spinal cord injury. RNA Biol. 15, 1071-1080. doi: 10.1080/15476286.2018.1493333

Zhang, M., Zhao, K., Xu, X., Yang, Y., Yan, S., Wei, P., et al. (2018). A peptide encoded by circular form of LINC-PINT suppresses oncogenic transcriptional elongation in glioblastoma. Nat. Commun. 9:4475. doi: 10.1038/s41467-01806862-2

Zhao, J., Qin, B., Nikolay, R., Spahn, C. M. T., and Zhang, G. (2019). Translatomics: the global view of translation. Int. J. Mol. Sci. 20:212. doi: 10.3390/ijms20010212

Zheng, G., Qin, Y., Clark, W. C., Dai, Q., Yi, C., He, C., et al. (2015). Efficient and quantitative high-throughput tRNA sequencing. Nat. Methods 12, 835-837. doi: 10.1038/nmeth.3478

Zyryanova, A. F., Weis, F., Faille, A., Alard, A. A., Crespillo-Casado, A., Sekine, Y., et al. (2018). Binding of ISRIB reveals a regulatory site in the nucleotide exchange factor eIF2B. Science 359, 1533-1536. doi: 10.1126/science.aar5129

Conflict of Interest: The authors declare that the research was conducted in the absence of any commercial or financial relationships that could be construed as a potential conflict of interest.

Copyright (c) 2020 Zhang, Chen, Wang, Zhang, Chen and Zhou. This is an openaccess article distributed under the terms of the Creative Commons Attribution License (CC BY). The use, distribution or reproduction in other forums is permitted, provided the original author(s) and the copyright owner(s) are credited and that the original publication in this journal is cited, in accordance with accepted academic practice. No use, distribution or reproduction is permitted which does not comply with these terms. 